\title{
Review \\ The Temperature Dependence of Deformation Behaviors in High-Entropy Alloys: A Review
}

\author{
Pengfei Wu, Kefu Gan *(D), Dingshun Yan and Zhiming Li *(D) \\ School of Materials Science and Engineering, Central South University, Changsha 410083, China; \\ pengfeiwu@csu.edu.cn (P.W.); ds.yan@csu.edu.cn (D.Y.) \\ * Correspondence: gankefu@csu.edu.cn (K.G.); lizhiming@csu.edu.cn (Z.L.)
}

Citation: Wu, P.; Gan, K.; Yan, D.; Li, Z.

The Temperature Dependence of

Deformation Behaviors in

High-Entropy Alloys: A Review.

Metals 2021, 11, 2005.

https://doi.org/10.3390/

met11122005

Academic Editor: Sergey

V. Zherebtsov

Received: 10 November 2021

Accepted: 10 December 2021

Published: 12 December 2021

Publisher's Note: MDPI stays neutral with regard to jurisdictional claims in published maps and institutional affiliations.

Copyright: (c) 2021 by the authors. Licensee MDPI, Basel, Switzerland. This article is an open access article distributed under the terms and conditions of the Creative Commons Attribution (CC BY) license (https:// creativecommons.org/licenses/by/ $4.0 /)$.

\begin{abstract}
Over the past seventeen years, deformation behaviors of various types of high-entropy alloys (HEAs) have been investigated within a wide temperature range, from cryogenic to high temperatures, to demonstrate the excellent performance of HEAs under extreme conditions. It has been suggested that the dominated deformation mechanisms in HEAs would be varied with respect to the environmental temperatures, which significantly alters the mechanical properties. In this article, we systematically review the temperature-dependent mechanical behaviors, as well as the corresponding mechanisms of various types of HEAs, aiming to provide a comprehensive and up-todate understanding of the recent progress achieved on this subject. More specifically, we summarize the deformation behaviors and microscale mechanisms of single-phase HEAs, metastable HEAs, precipitates-hardened HEAs and multiphase HEAs, at cryogenic, room and elevated temperatures. The possible strategies for strengthening and toughening HEAs at different temperatures are also discussed to provide new insights for further alloy development.
\end{abstract}

Keywords: high-entropy alloy; temperature; deformation mechanisms

\section{Introduction}

The rapid development of modern industry requires high-performance engineering materials that can service in harsh environments, for instance, high strength and stability should be maintained for turbine blades at high temperatures and rocket tanks serviced in cryogenic environments. However, the endeavor on conventional alloys to achieve sufficiently high performance encounters bottlenecks, i.e., it is hard to further develop new alloys with enhanced performance based on traditional alloy systems. In the last nearly two decades, the concept of high-entropy alloys (HEAs) containing multi-principal elements breaks the restrictions of traditional alloy design principles, which enables the alloy composition to expand from the initial corner to the center region of the phase diagram [1,2]. Various HEAs have been reported to show high strength [3,4], high corrosion resistance [5-8], good thermal stability [9], excellent wear resistance [10] or impressive magnetic properties [11,12]. Even some of them have achieved a good combination of mechanical and functional properties [11,13]. These facts suggest that the HEAs have great potential in practical applications.

In recent years, HEA design has been developed from single-phase equiatomic to non-equiatomic even multiphase variants to pursue a better synergy of multiple properties, e.g., strength and ductility [14] or strength and anti-corrosion performance [15,16]. The expanded range of chemical composition promotes the development of a mass of new HEAs, and therefore more deformation mechanisms, such as mechanical twinning and phase transformation have been involved due to that the mechanisms sensitively depend on the chemical composition and microstructure. Theoretically, both displacive phase transformation and mechanical twinning are motivated by the slip of Shockley partial dislocations [17]. Further, dislocation behavior is closely related to the thermal conditions; thus, the mechanical properties of HEAs are strongly dependent on temperatures. For 
instance, with increasing temperature from $77 \mathrm{~K}$ to $1173 \mathrm{~K}$, the strength and ductility of the Cantor alloy are gradually degraded $[18,19]$ and a similar scenario is also found in the $\mathrm{Al}_{0.1} \mathrm{FeCoCrNi}($ at. \%) HEA $[20,21]$. However, the elongation values of the metastable $\mathrm{Fe}_{50} \mathrm{Mn}_{30} \mathrm{Co}_{10} \mathrm{Cr}_{10}$ (at. \%) [22] and $\mathrm{Fe}_{49.5} \mathrm{Mn}_{30} \mathrm{Co}_{10} \mathrm{Cr}_{10} \mathrm{C}_{0.5}$ (at. \%) [23] HEAs at cryogenic temperatures are lower than those at room temperature, respectively. The fact indicates that the influences of deformation temperature on the mechanical properties of various types of HEAs are different, implying that the underlying deformation mechanisms are changed accordingly.

A large number of investigations on the mechanical behaviors of various HEAs at different temperatures have been carried out, and the corresponding deformation mechanisms have also been elaborated to some extent in recent years. However, the correlations between deformation temperatures and fundamental mechanisms for the various HEAs are not fully clear when only considering the individual investigation. Therefore, this review aims to summarize the temperature-dependent deformation behaviors and the underlying mechanisms in HEAs, which is not only significant for further understanding the deformation mechanisms of HEAs but also important for promoting the engineering applications of HEAs in different environments. The review involves various HEA compositions reported in different articles. To fully comply with the original scientific intentions for alloy design, the designations of all alloys throughout this review are kept as their forms presented in the respectively cited publications.

\section{Brief Review of the Temperature Effect on Dislocation Behavior}

To facilitate a better understanding of the mechanisms responsible for the temperature dependence of deformation behavior in the various HEAs, we first briefly review the theoretical effects of temperature on dislocation behavior. Dislocation movement is the microscale performance for crystals to coordinate the plastic deformation. The energy for dislocations overcoming the barrier consists of thermal $(\Delta G)$ and athermal $(\Delta W)$ parts. Therefore, the increase of temperature provides part of thermal activation energy, thus decreasing the applied stress for triggering the movement of dislocations, as shown by the schematic diagram in Figure 1. In addition, the dependence of macroscopic shear strain rate $(\dot{\varepsilon})$ on temperature can be given by [24]:

$$
\dot{\varepsilon}=b \rho v_{0} \exp \left(-\frac{\Delta G(\tau)}{k T}\right)
$$

where $b, \rho, v_{0}, k$ and $T$ are the Burgers vector, the density of mobile dislocations, the dislocation velocity, Boltzmann constant and temperature, respectively; $\Delta G(\tau)$ is the free energy of dislocation activation to overcome the obstacle under an applied stress $\tau$. This indicates that the dislocation motion becomes easier and the strain rate would also increase with the increase of temperature.

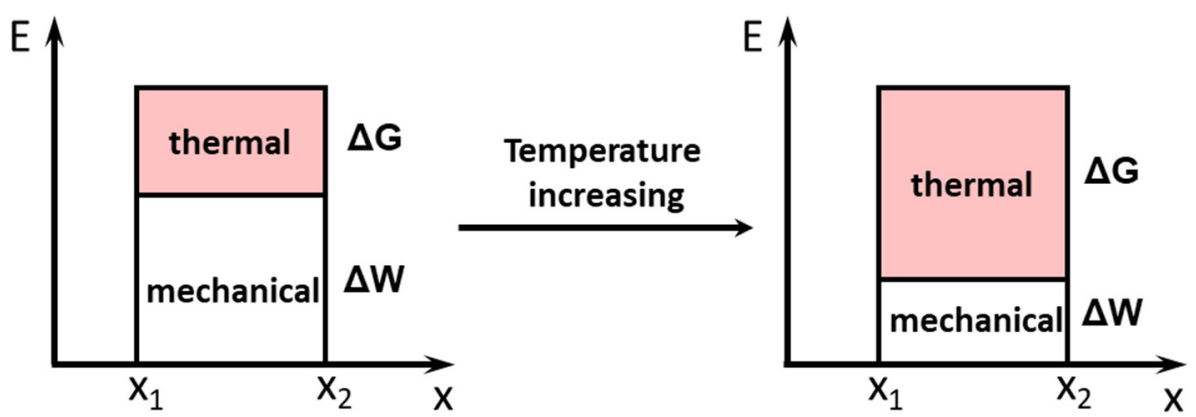

Figure 1. Schematics showing the change of activation energy on the dislocation for overcoming a localized obstacle with the increase of temperature, data from ref. [17]. 
For face-centered cubic (FCC) structured materials, the dislocation behavior is strongly related to the value of stacking fault energy (SFE). Generally, the displacive phase transformation and the corresponding transformation-induced plasticity (TRIP) effect occur in low-SFE alloys (SFE $\leq 15 \mathrm{~mJ} / \mathrm{m}^{2}$ ), and the deformation behavior of moderate SFE (15 $\mathrm{mJ} / \mathrm{m}^{2}<\mathrm{SFE}<45 \mathrm{~mJ} / \mathrm{m}^{2}$ ) alloys can be dominated by mechanical twinning and the corresponding twinning-induced plasticity (TWIP) effect. At a high level of SFE (SFE $\geq 45 \mathrm{~mJ} / \mathrm{m}^{2}$ ), dislocation glide is usually the main mechanism. Note that the threshold SFE values for the various mechanisms are not fully consistent in literature but a little disparity is usually presented [25]. The value of SFE $\left(\gamma_{0}\right)$ and the corresponding temperature-dependent change $\left(\frac{d \gamma_{0}}{d T}\right)$ can be given by the following equations [26]:

$$
\begin{aligned}
\gamma_{0}=\frac{\Delta G^{\gamma \rightarrow \varepsilon}}{8.4 V^{\frac{2}{3}}} & =\frac{\Delta H^{\gamma \rightarrow \varepsilon}-T \Delta S^{\gamma \rightarrow \varepsilon}}{8.4 V^{\frac{2}{3}}} \\
\frac{d \gamma_{0}}{d T} & =-\frac{\Delta S^{\gamma \rightarrow \varepsilon}}{8.4 V^{\frac{2}{3}}}
\end{aligned}
$$

where $\Delta G^{\gamma \rightarrow \varepsilon}, \Delta H^{\gamma \rightarrow \varepsilon}$ and $\Delta S^{\gamma \rightarrow \varepsilon}$ are the Gibbs molar free energy, enthalpy and entropy difference between FCC phase $(\gamma)$ and hexagonal close-packed (HCP) phase $(\varepsilon)$, respectively; $V$ is the molar volume. $\Delta S^{\gamma \rightarrow \varepsilon}$ is negative for the phase transformation process, consequently, $\frac{d \gamma_{0}}{d T}>0$, which suggests that SFE has a positive relation with temperature, namely, the increase of temperature would lead to the increase of SFE.

Therefore, the constriction and cross-slip of dislocations can be thermally activated since the vibration of atoms of dislocation partials is thermally promoted around their equilibrium position. The cross-slip frequency of dislocations for a given applied shear stress $\tau$ is expressed by $[27,28]$ :

$$
\Gamma_{Q}=v_{D}\left(\frac{\tau}{\tau_{M}}\right) \exp \left(\frac{A}{k T}\right)
$$

where $\tau_{M}$ is the shear stress which has to be applied to enforce cross-slip without thermal activation. $A$ is the so-called cross-slip constant. Both $A$ and $\tau_{M}$ depend on SFE. The increased temperature can promote the constriction of extended dislocations; thus, dislocations are prone to cross-slip at high temperatures rather than dissociation. Accordingly, at elevated temperatures, the dissociation of perfect dislocations becomes difficult. Therefore, both displacive phase transformation and mechanical twinning are suppressed at high temperatures in the majority of alloys.

Note that at very high temperatures, i.e., above half of the melting temperature, additional diffusion-controlled plasticity becomes more active, which also alleviates the flow stress compared with that under an athermal condition. The activation energy compensated by environmental heat can promote the atomic diffusion of defects, which commonly leads to a time- and temperature-dependent deformation behavior, i.e., creep. For simplifying the creep model, mobile dislocation can be regarded as a rod moving in the viscoelastic medium. Then, the relationship between steady-state creep rate $\left(\dot{\varepsilon}_{S S}\right)$ and applied stress $(\sigma)$ follows the phenomenological power law equation [29]:

$$
\dot{\varepsilon}_{S S}=A \sigma^{n} \exp \left(-\frac{Q_{C}}{R T}\right)
$$

where $A$ is a material constant, $n$ is the stress exponent, $Q_{C}$ is the apparent activation energy of creep, $\mathrm{R}$ is the ideal gas constant and $\mathrm{T}$ is the absolute temperature. The $n$ values are below the commonly observed values (4-7) for dislocation climb-controlled creep but above that $(\sim 3)$ for viscous glide-controlled creep [30]. 


\section{Mechanical Behaviors of Typical HEAs at Various Temperatures}

The equiatomic HEAs had been a research hotspot at early stages, but later studies revealed that the maximum configurational entropy, i.e., guaranteeing each element in an equiatomic ratio, is not essential to achieve good mechanical performance. Thus, a mass of non-equiatomic HEAs with different compositions have been developed [14,18,31-35], which present different mechanical properties affected by temperature, as seen in Figure 2. Due to the limited length of the present review, we discuss four types of HEAs that can well represent the mainstream of reported HEAs so far, i.e., single-phase HEAs, metastable HEAs, precipitates-hardened HEAs and multiphase HEAs.
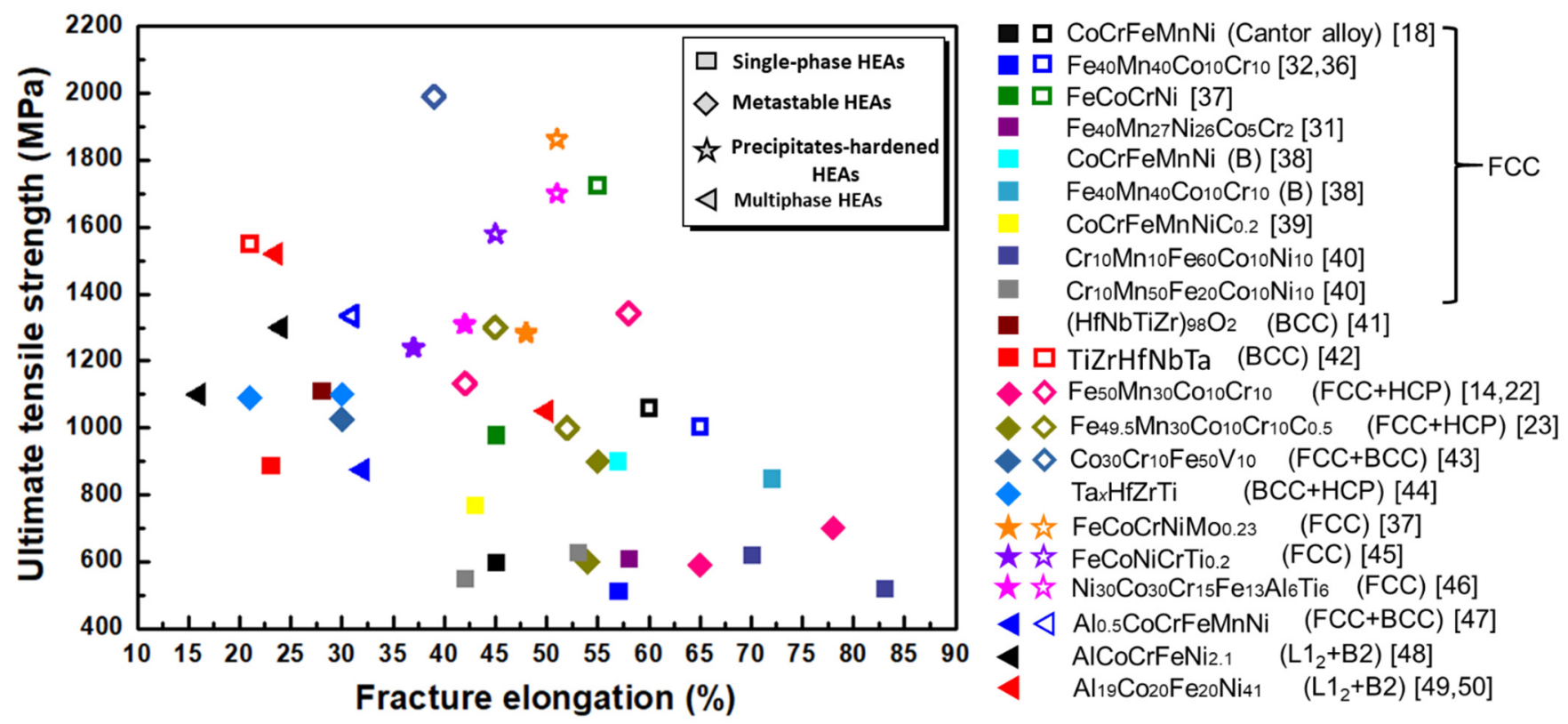

Figure 2. The ultimate tensile strength versus fracture elongation of different types of HEAs, data from $[14,18,22,23,31,32,36-$ 50]. Solid and hollow-out icons represent the results at room and cryogenic temperatures, respectively. $\mathrm{CoCrFeMnNi(B)}$ and $\mathrm{Fe}_{40} \mathrm{Mn}_{40} \mathrm{Co}_{10} \mathrm{Cr}_{10}$ (B) refer to Boron (30 ppm) doped equiatomic $\mathrm{CoCrFeMnNi}$ and non-equiatomic $\mathrm{Fe}_{40} \mathrm{Mn}_{40} \mathrm{Co}_{10} \mathrm{Cr}_{10}$ (at. \%) alloys, respectively.

\subsection{Single-Phase HEAs}

Single-phase HEAs show solid-solution structure with multi-principal elements. Most of them display relatively low strength and high ductility, as shown in Figure 2. Among the well-established single-phase HEAs, the FCC and body-centered cubic (BCC) HEAs have been widely studied over the past years, while the HCP HEAs have been rarely reported. Therefore, in this section, we mainly focus on the deformation behaviors and related mechanisms of some typical FCC and BCC HEAs.

\subsubsection{Room-Temperature Deformation of Single-Phase HEAs}

Since the invention of FCC structured equiatomic CoCrFeMnNi HEA (Cantor alloy) in 2004 [51], a large number of multicomponent FCC HEAs have been developed so far. According to the early studies on the deformation behavior of Cantor alloy, dislocation slip prevails throughout the tensile deformation, while mechanical twinning participates at high strain levels at room temperature [52]. In a quaternary equiatomic FeCoCrNi HEA, dislocation slip governs the plastic deformation. The fact indicates that the quaternary equiatomic FeCoCrNi HEA owns a higher SFE than the quinary Cantor alloy [37].

In comparison with the equiatomic HEAs, the non-equiatomic single-phase HEAs also show good strength and ductility at room temperature. For instance, the non-equiatomic $\mathrm{Fe}_{40} \mathrm{Mn}_{27} \mathrm{Ni}_{26} \mathrm{Co}_{5} \mathrm{Cr}_{2}$ (at. \%) [31] and $\mathrm{Cr}_{10} \mathrm{Mn}_{50} \mathrm{Fe}_{20} \mathrm{Co}_{10} \mathrm{Ni}_{10}$ (at. \%) [40] HEAs deriv- 
ing from the Cantor alloy show moderate strength and considerable ductility which is higher than that of the Cantor alloy, as shown in Figure 2. Although only dislocation slip prevails on the deformation of both alloys, a mass of dislocation cells is observed due to the frequent cross-slip of dislocations, which significantly enhances the work hardening rate and further improves the ductility. The TWIP effect also can be tailored and prevalent in $\mathrm{Fe}_{40} \mathrm{Mn}_{40} \mathrm{Co}_{10} \mathrm{Cr}_{10}$ (at. \%) [32], $\mathrm{Cr}_{20} \mathrm{Mn}_{15} \mathrm{Fe}_{34} \mathrm{Co}_{20} \mathrm{Ni}_{11}$ (at. \%) [53] and $\mathrm{Cr}_{10} \mathrm{Mn}_{10} \mathrm{Fe}_{60} \mathrm{Co}_{10} \mathrm{Ni}_{10}$ (at. \%) [40] HEAs. Since the SFEs of these alloys are less than 30 $\mathrm{mJ} / \mathrm{m}^{2}$, perfect dislocations readily dissociate and form stacking faults. The dynamic Hall-Petch effect induced by the refining effect of mechanical twins enables them to have desirable ductility. Those investigations suggest that the non-equiatomic design strategy can provide more space to tune phase stability and trigger abundant deformation mechanisms for achieving better synergy of strength and ductility.

Due to the close atomic radii of principal elements, the lattice distortion is not prominent in the CoCrFeMnNi HEA system [54,55]. Rationally adding interstitial elements, such as $B, C$ and $N$, into the HEA matrix is a simple and economical strategy to strengthen the alloys [35,39,56-59]. The interstitial atoms occupying the tetrahedral and octahedral interstices significantly enhance the resistance against mobile dislocations by inducing spatial lattice fluctuations $[60,61]$. The addition of $C$ can tune the phase stability and suppress the displacive phase transformation of CoCrFeMnNi HEAs system [23,35,62]. The high-dose addition of $\mathrm{C}$ may induce the formation of carbides, which facilitates the crack nucleation and propagation, and consequently leads to the earlier fracture during deformation [39]. It is also found that B can strengthen the grain boundaries (GBs) via segregating there; thus, the strength of B-doped equiatomic $\mathrm{CoCrFeMnNi}$ and non-equiatomic $\mathrm{Fe}_{40} \mathrm{Mn}_{40} \mathrm{Co}_{10} \mathrm{Cr}_{10}$ (at. \%) HEAs can be significantly enhanced compared with B-free HEAs [38], as illustrated in Figure 2. Furthermore, B-doped HEAs exhibit similar work hardening responses and distribution of twin thickness with the B-free counterpart, which indicates that B does not profoundly affect SFEs of these HEAs.

Compared with single-phase FCC HEAs, BCC HEAs, e.g., equiatomic NbMoTaW, VNbMoTaW, HfNbTiZr and TiZrHfNbTa HEAs [63-70], are much stronger but more brittle due to the poor mobility of perfect dislocations at room temperature or the lower temperatures. The deformation mechanism of the BCC equiatomic TiZrHfNbTa HEA is dominated by the slip of screw dislocation, while the work hardening rate is highly dependent on the dislocation propagation $[69,70]$. For details, the evolution of working hardening rate in the BCC refractory HEAs can be divided into three distinctive stages [70]: (i) in the beginning, a Peierls mechanism dominates the plasticity by inducing high friction stress exerted along the [111] directions against the activation of dislocation slip; (ii) then with dislocation propagation, a mass of dislocation bands is progressively generated. Dislocations are also partitioned to soft zones with few dislocations at hard zones containing highly dense dislocation debris; (iii) with the strain further increased, the density of dislocation considerably increases and their distribution turns more homogeneous. The planar motion and cross-slip of jogged screw dislocations become more active, which gradually form numerous debris.

The interstitial alloying strategy is also employed in BCC HEAs. For instance, it has been reported that adding interstitial $\mathrm{O}$ into the $\mathrm{BCC}$ refractory HfNbTiZr HEA generates ordered oxide complexes (OOCs), which prominently promotes the multiplication of dislocations via cross-slip then synchronically enhances the strength and ductility [41].

Bulk single-phase HCP HEAs and the corresponding deformation mechanisms are very rarely presented so far. As mentioned above, the FCC $\rightarrow \mathrm{HCP}$ displacive phase transformation can happen in the $\mathrm{Fe}_{50} \mathrm{Mn}_{30} \mathrm{Co}_{10} \mathrm{Cr}_{10}$ (at. \%) metastable HEA at room temperature [71]. Different from the conventional HCP alloys of which the deformation is dominated by single slip mode, the massive solid solution could tune the $\mathrm{c} / \mathrm{a}$ ratio of the transformed HCP phase in the metastable HEA and lead dislocation slip mode to shift from basal $<$ a $>$ or non-basal $<\mathrm{c}+\mathrm{a}>$ slip mode into mixed $<\mathrm{c}+\mathrm{a}>$ and $<\mathrm{a}>$ modes. Although the study presented in [59] focuses on the deformation of the microsized HCP phase in 
a metastable HEA, the finding provides useful insights for further designing strong and ductile HCP HEAs.

\subsubsection{Cryogenic-Temperature Deformation of Single-Phase HEAs}

It is known that the strength of many single-phase FCC metals dramatically increases at liquid nitrogen temperature compared to that at room temperature, because the decrease of temperature enhances the lattice friction stress. In contrast, BCC and part of HCP metals commonly lose their plasticity at cryogenic temperatures, presenting the so-called 'ductile to brittle transition' [72]. As shown in Figure 2, single-phase FCC HEAs usually show good mechanical properties at cryogenic temperature, the strength and ductility of which increase compared with those at room temperature, implying the transition of deformation mechanisms.

It has been reported that the extremely low temperature dramatically reduces the SFE of Cantor alloy [73]. Consequently, profuse mechanical twins are activated at a low temperature (e.g., $77 \mathrm{~K}$ ), which induces a strong dynamic Hall-Petch effect on improving the flow stress upon plastic deformation. In addition, twin-twin interaction gives rise to more pronounced work hardening compared with dislocation-dislocation and twindislocation interactions [74]. Since low temperatures lead to the high density of nanoscale twins in the vicinity of crack tips, the Cantor alloy displays a remarkable fracture toughness over $200 \mathrm{MPa} \cdot \mathrm{m}^{1 / 2}$ at crack initiation and rises to $>300 \mathrm{MPa} \cdot \mathrm{m}^{1 / 2}$ for stable crack growth at $77 \mathrm{~K}$ [75]. The SFE and related phase stability of some more HEAs can be reduced at cryogenic temperatures compared to that at room temperature. For instance, the TRIP mechanism can be triggered in $\mathrm{Fe}_{40} \mathrm{Mn}_{40} \mathrm{Co}_{10} \mathrm{Cr}_{10}$ (at. \%) [36,76] and $\mathrm{V}_{10} \mathrm{Cr}_{10} \mathrm{Co}_{30} \mathrm{Fe}_{45} \mathrm{Ni}_{5}$ (at. \%) [43] HEAs during deformation at cryogenic temperature, which significantly enhances the ductility of these alloys. Furthermore, the phase metastability of some BCC HEAs also can be awakened at low temperatures, e.g., the transformation from $B C C$ phase to non-closed packed hexagonal $\omega$ was observed in the equiatomic TiZrHfNbTa HEA on tension [42]. Combining the other mechanisms including $\{112\}<111>$ mechanicaltwinning and screw dislocation glide, the equiatomic TiZrHfNbTa HEA thus shows a high strength-ductility combination at cryogenic temperature.

In addition, serration behavior is commonly observed in the deformation of HEAs at cryogenic temperatures. Theoretically, such a scenario can be attributed to mechanical or thermomechanical instability. It has been reported that the serration behavior in the stress-strain curve of $\mathrm{Al}_{0.1} \mathrm{CoCrFeNi}$ (at. \%) HEA at $77 \mathrm{~K}$ is ascribed to the presence of nanoscale deformation twins that are absent at $293 \mathrm{~K}$ [21], similar to the case of intermittent nucleation of twins in single-crystal $\mathrm{Zn}$ deformed at room temperature [28]. Sudden massive dislocation proliferation can also lead to the serration behavior in the Cantor alloy deformed at extremely low temperatures, e.g., $4.2 \mathrm{~K}$ [77]. Besides this, it has been found recently that the serration behavior of the Cantor alloy varies with the temperature due to thermodynamic instability [78].

\subsubsection{High-Temperature Deformation of Single-Phase HEAs}

An investigation on the high-temperature deformation behavior of the Cantor alloy, conducted by Woo et. al [79] via in situ neutron diffraction, has revealed that the microscale deformation mechanism changes when the temperature increases from $800 \mathrm{~K}$ to $1000 \mathrm{~K}$. The dominant deformation at $800 \mathrm{~K}$ is dislocation slip while it turns to dislocation creep at $1000 \mathrm{~K}$ because dislocation regeneration and annihilation reach an equilibrium state at that temperature. Dislocation behaviors at high temperatures are also dependent on the applied strain rate. At low strain rates $\left(<2 \times 10^{-5} \mathrm{~s}^{-1}\right)$, the deformation of the Cantor alloy is governed by the viscous glide of dislocations since the stress exponent is less than 3 and the activation energy is about $280 \mathrm{~kJ} / \mathrm{mol}$; at high strain rates $\left(>2 \times 10^{-5} \mathrm{~s}^{-1}\right)$, the deformation is controlled by dislocation climb by virtue of the diffusion of $\mathrm{Ni}$ atoms because the stress exponent and the activation energy are increased to $\sim 5$ and $\sim 330 \mathrm{~kJ} / \mathrm{mol}$, respectively [80].

Besides this, it has been found that, upon increasing the temperature from $298 \mathrm{~K}$ to $973 \mathrm{~K}$, both strength and ductility of the Cantor alloy are degraded, as indicated in Figure 
$3 a[18,80,81]$. The origin of high-temperature embrittlement in that alloy is the segregation of $\mathrm{Cr}, \mathrm{Ni}$ and $\mathrm{Mn}$ at GBs [19]. These segregated elements mutually repel and weaken the cohesion of GBs (as shown in Figure 3b), which further lead to intergranular fracture on high-temperature deformation. The segregation behavior is rational. Previously, Gu et al. [82,83] and Li et al. [84] found the Cr-rich and Ni-rich precipitates in the long-time annealed cold-rolled Cantor alloy. To alleviate the high-temperature embrittlement of the HEA, Ming et.al. [19] increased the content of $\mathrm{Cr}$ and used the pre-existing Cr-rich $\sigma$ phase to absorb $\mathrm{Cr}$ elements and repel $\mathrm{Ni}$ and $\mathrm{Mn}$ at GBs at high temperatures, which efficiently suppressed the elemental segregation at GBs thus enhanced the ductility of the $\mathrm{Co}_{20} \mathrm{Cr}_{26} \mathrm{Fe}_{20} \mathrm{Mn}_{20} \mathrm{Ni}_{14}$ (at. \%) alloy at high temperatures, as illustrated in Figure 3a,c. Moreover, the previous research [85] indicated that the occurrence of mechanical twinning was also suppressed by high temperatures, which lowered the strain hardening ability of TWIP HEAs. Apart from the aforementioned mechanisms, GB sliding can also lead to high-temperature embrittlement, which has been reported in several HEAs [9,86]. Thus, GB stability is a key factor for the resistance to high-temperature deformation. In terms of this issue, $\mathrm{Wu}$ et al. [87] proposed a strategy of building serrated grain boundaries (SEGBs) to enhance the mechanical stabilization of GB. Such SEGBs can improve the immunity of the alloy to early fracture along GBs by eliminating the severe strain location and limiting the slide of GB on high-temperature tension. Another strategy utilizing carbides to maintain strength and ductility at high temperatures will be introduced in Section 3.3.
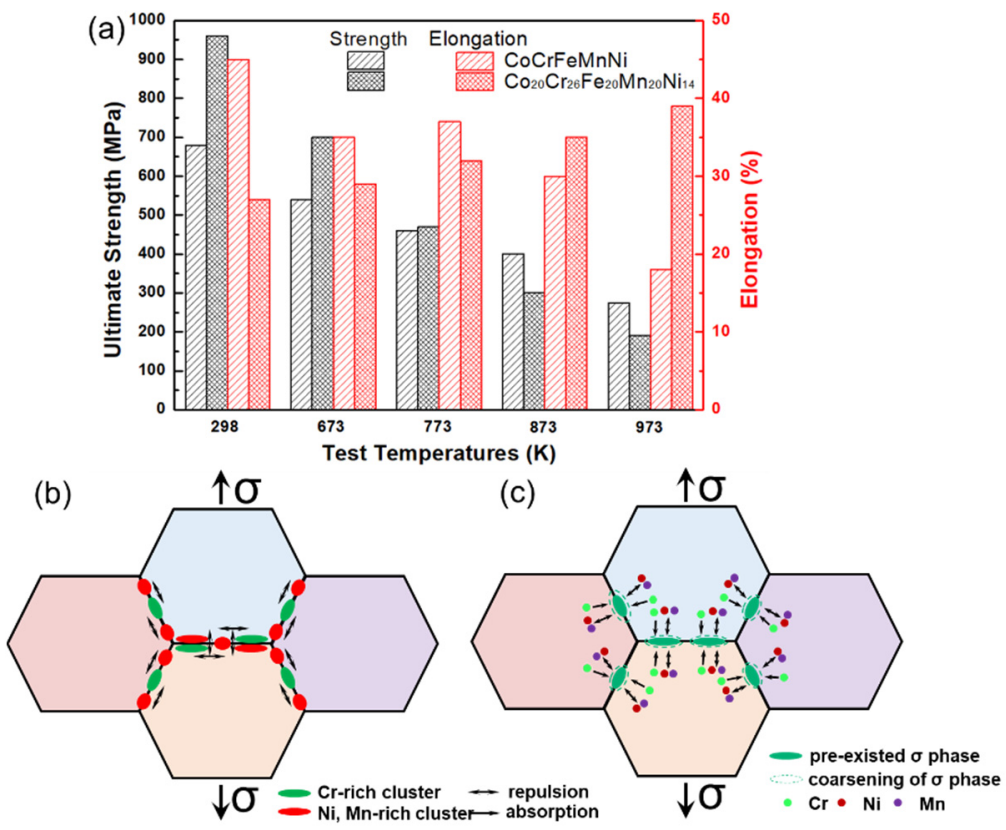

Figure 3. (a) Mechanical properties of the single-phase coarse-grained CoCrFeMnNi and $\mathrm{Co}_{20} \mathrm{Cr}_{26} \mathrm{Fe}_{20} \mathrm{Mn}_{20} \mathrm{Ni}_{14}$ (at. \%) HEAs at different temperatures (data points are adapted from reference [19]). Schematic diagrams of GB segregation at high temperatures for (b) CoCrFeMnNi (at. \%) and (c) $\mathrm{Co}_{20} \mathrm{Cr}_{26} \mathrm{Fe}_{20} \mathrm{Mn}_{20} \mathrm{Ni}_{14}$ (at. \%) HEAs.

Dynamic recovery and recrystallization behaviors commonly occur during the hot deformation processes. Previous studies indicate that GBs are preferential sites for recrystallization, which commonly forms a necklace structure along GBs in both FCC and BCC HEAs, involving equiatomic CoCrFeMnNi (FCC) [88,89], TiZrHfNbTa (BCC) [90] and $\mathrm{AlCoCrFeNi}$ (BCC) [91] HEAs. In AlCoCrFeNi HEA [91], a refined duplex microstructure is produced via hot compression at $1373 \mathrm{~K}$ at a strain rate of $10^{-3} \cdot \mathrm{s}^{-1}$ through dynamic recrystallization, which reconstructs the shape of FCC grains through phase transformation during the hot deformation. The scenario is also observed in the equiatomic TiZrHfNbTa HEA deformed at $1273 \mathrm{~K}$ and a strain rate of $10^{-3} \mathrm{~s}^{-1}$ [92]. Besides the aforementioned 
necklace structure composed of fine recrystallized grains, micro-textures with prominent slip traces of dislocations are also observed to form in the unrecrystallized regions, and such textures can be intensified with increasing the strain, due to the significant GB slide during the high-temperature deformation [92]. Since the sluggish diffusion and solute drag effect resulted from the retarding effect of $\mathrm{Al}, \mathrm{Al}_{0.3} \mathrm{CoCrFeNi}$ (at. \%) $\mathrm{HEA}(513 \mathrm{~kJ} / \mathrm{mol}$ ) has relatively high activation energy compared with high Mn TWIP steel (377 kJ/mol), Ni-based superalloy $(474 \mathrm{~kJ} / \mathrm{mol})$, austenitic stainless steel $(375 \mathrm{~kJ} / \mathrm{mol})$ and the Cantor alloy (350 $\mathrm{kJ} / \mathrm{mol}$ ). Further, the significant retarding effect of $\mathrm{Al}$ plays a role in the high-temperature deformation of dual-phase $\mathrm{Al}_{0} \cdot{ }_{5} \mathrm{CoCrFeNi}$ (at. \%) HEA $[93,94]$. Specifically, the solute atmosphere of $\mathrm{Al}$ atoms around dislocation cores prevents movement of dislocations, but the stress abruptly decreases once dislocation overcomes the barrier, resulting in a serration behavior in stress-strain curves $[93,94]$.

\subsection{Metastable HEAs}

The trade-off of strength and ductility severely limits the application of structural materials. Inspired by the non-equiatomic design strategy, the metastable HEAs have been proposed, in which the displacive phase transformation triggered by the slip of partial dislocations upon deformation enables to have a desirable strain hardening capability [14,34,95]. Thus, the metastable-engineering strategy gives a potential solution to such strength-ductility trade-off. The displacive martensite transformation is sensitive to the temperature and the corresponding dislocation behavior should be more complicated than that of single-phase HEAs.

\subsubsection{Room-Temperature Deformation of Metastable HEAs}

It is known that plastic deformation of metastable HEAs is accommodated through a set of deformation mechanisms under ambient temperature. Typically, for the first metastable $\mathrm{Fe}_{50} \mathrm{Mn}_{30} \mathrm{Co}_{10} \mathrm{Cr}_{10}$ (at. \%) HEA proposed by Li et al. [14], at the early stage of deformation, staking faults triggered in the FCC phase by mobile Shockley partials and massive interphases generated via displacive martensite transformation significantly hinder dislocation slip, which leads to the significant strain hardening. Then the displacive phase transformation turns to be the dominated deformation mechanism with further straining. As the applied strain increases further, dislocations and mechanical nano-twins can be activated in the HCP phase, contributing to strain hardening and then postponing necking. A study [34] furtherly revealed that the decreased grain size of the FCC matrix and the increased initial HCP phase fraction can lead to a lower fraction of the transformed HCP phase at certain strains. It is generally recognized that the displacive phase transformation process is unidirectional at room temperature. However, Lu et al. [96] found that the transformation mechanism was bidirectional in the metastable $\mathrm{Fe}_{50} \mathrm{Mn}_{30} \mathrm{Co}_{10} \mathrm{Cr}_{10}$ (at. \%) HEA, i.e., forward (FCC $\rightarrow \mathrm{HCP}$ ) and backward ( $\mathrm{HCP} \rightarrow \mathrm{FCC}$ ) phase transformations both exist under room temperature tensile deformation, denoted as the 'bidirectional transformation-induced plasticity (B-TRIP)' effect. Under the assistance of a serial of mechanisms, most metastable HEAs display better synergy of strength and ductility compared with the majority of stable single-phase HEAs at room temperature, as shown in Figure 2. The metastability engineering strategy of HEAs thus provides a promising direction for the design of strong and ductile alloys.

Similar to the case of stable single-phase FCC HEAs, the addition of interstitial atoms can also tune the phase stability of metastable HEAs, then the deformation mechanisms are changed accordingly (seen in Figure 4). In a representative 0.5 at. \% C-doped metastable $\mathrm{Fe}_{49.5} \mathrm{Mn}_{30} \mathrm{Co}_{10} \mathrm{Cr}_{10} \mathrm{C}_{0.5}$ (at. \%) HEA, mechanical twins, stacking faults and dislocations are observed at the early uniform deformation stage, but the occurrence of the displacive phase transformation is significantly postponed to the higher strain regime since interstitial $\mathrm{C}$ stabilizes the FCC matrix [34,35]. Furthermore, the displacive phase transformation was found to be suppressed in the $\mathrm{C}-\mathrm{N}$ co-doped $\mathrm{Fe}_{48.5} \mathrm{Mn}_{30} \mathrm{Co}_{10} \mathrm{Cr}_{10} \mathrm{C}_{0.5} \mathrm{~N}_{1.0}$ (at. \%) on tension, which suggested that the high content of interstitial atoms efficiently enhanced the SFE of the metastable HEA [97]. Note that such C and N co-doped HEA subjected to 
severe deformation would exhibit the martensite transformation again [98], indicating that the phase metastability could be awakened by modifying the strain state. In the case of the recently reported $\mathrm{Si}_{x} \mathrm{~V}_{9-x} \mathrm{Cr}_{10} \mathrm{Mn}_{5} \mathrm{Fe}_{46} \mathrm{Co}_{30}$ (at. \%) HEA [99], the initial FCC matrix would transfer to HCP and BCC phases successively with increasing the applied strain, which significantly enhances the strength and ductility. Moreover, the TRIP effect is also detected in some BCC HEAs. For instance, BCC $\rightarrow \mathrm{HCP}$ transformation is observed in non-equiatomic $\mathrm{Ti}_{35} \mathrm{Zr}_{27.5} \mathrm{Hf}_{27.5} \mathrm{Nb}_{5} \mathrm{Ta}_{5}$ (at. \%) [100] and $\mathrm{Ta}_{x} \mathrm{HfZrTi}(x=0.4,0.5,0.6)$ (at. $\%$ ) [44] HEAs, which enables them of a prominent strain hardening and puts off the onset of necking; as a consequence, a higher ductility is obtained compared to the equiatomic counterpart without phase transformation.

As discussed above, deformation mechanisms of metastable HEAs can be altered by minor addition of interstitial elements, but the excess addition of interstitial atoms may worsen the ductility of metastable HEAs [23,76]. For this problem, the hierarchical microstructure design is of benefit to achieve the considerable work hardening capacity and hence the strength-ductility synergy of such interstitial HEAs. Su et al. [101] proposed a trimodal microstructure containing small recrystallized grains, medium-sized recrystallized grains and large retained un-recrystallization grains by using a special mechanical heat treatment to achieve an excellent strength-ductility synergy in the metastable $\mathrm{Fe}_{49.5} \mathrm{Mn}_{30} \mathrm{Co}_{10} \mathrm{Cr}_{10} \mathrm{C}_{0.5}$ (at. \%) HEA (Figure 4). In comparison with the bimodal structured sample, such trimodal-structure sample exhibits a continuous strain hardening with four stages: (i) the work hardening rate continuously decreases at a strain range of $0-2 \%$ resulted by the rearrangement of the dislocations; (ii) a steep increase at low strains (2-5\%) in the work hardening rate due to the nucleation of HCP-martensite lamellae and nanotwins in the medium-sized recrystallized grains; (iii) the work hardening rate reduces at the strain range of $5-18 \%$ ascribed to the growth of HCP-martensite and mechanical twins prevail in medium-sized grains; (iv) the work hardening rate declines with a lower decreasing slope over the strain of $18 \%$ due to the nucleation and growth of HCP-martensite and twins in the ultrafine recrystallized grains [101]. Consequently, the ductility of the trimodal structure specimen is significantly improved. The strategy of designing hierarchical structures was also applied to the metastable $\mathrm{Co}_{20} \mathrm{Cr}_{20} \mathrm{Fe}_{40} \mathrm{Mn}_{10} \mathrm{Ni}_{10}$ (at. \%) HEA [33], in which $\sim 8 \%$ (vol. \%) unrecrystallized zones significantly improved the yield strength $\left(\sigma_{\mathrm{y}}: \sim 589\right.$ $\mathrm{MPa})$ and the ultimate tensile strength $\left(\sigma_{\mathrm{b}}: \sim 865 \mathrm{MPa}\right)$, and maintained a high elongation $(\sim 69.1 \%)$, compared with the fully recrystallized counterpart ( 375 MPa, 785 MPa and $\sim 77.5 \%$, respectively).

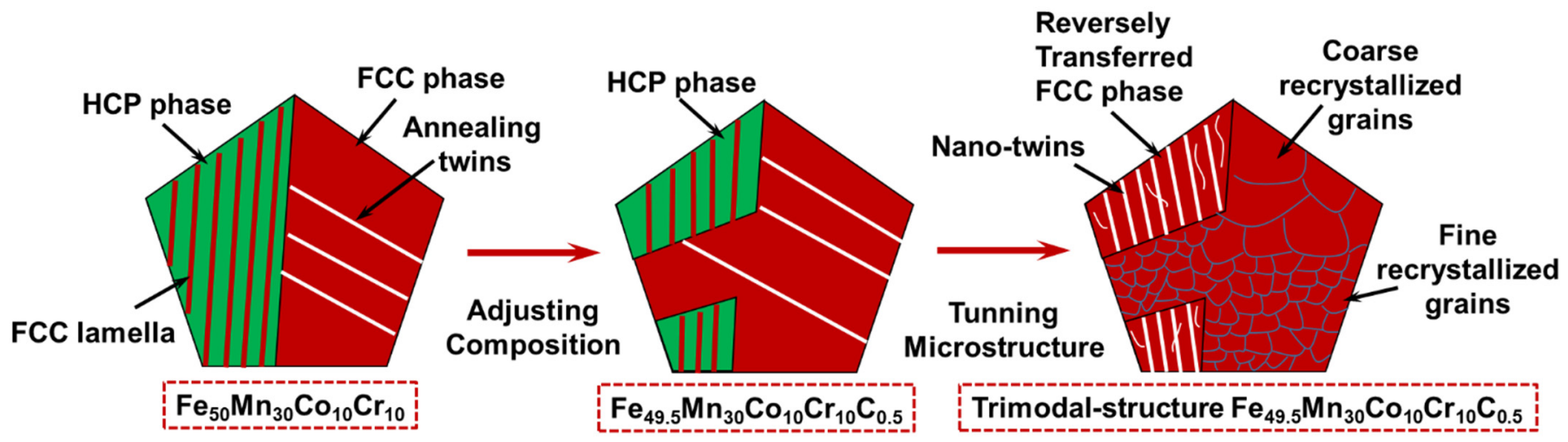

Figure 4. Tuning deformation behavior of the typical metastable $\mathrm{Fe}_{50} \mathrm{Mn}_{30} \mathrm{Co}_{10} \mathrm{Cr}_{10}$ (at. \%) HEA by altering chemical composition and microstructure.

\subsubsection{Cryogenic-Temperature Deformation of Metastable HEAS}

The deformation-driven phase transformation usually happens in low-SFE alloys. Since decreasing the temperature can furtherly lower SFE and increase flow stress, mechan- 
ical twinning and displacive phase transformation can be promoted at cryogenic temperatures. For example, when the metastable $\mathrm{Fe}_{50} \mathrm{Mn}_{30} \mathrm{Co}_{10} \mathrm{Cr}_{10}$ (at. \%) and $\mathrm{Fe}_{49.5} \mathrm{Mn}_{30} \mathrm{Co}_{10} \mathrm{Cr}_{10}$ $\mathrm{C}_{0.5}$ (at. \%) HEAs are strained at low temperatures, the fractions of transformed HCP phase are much higher than that at $293 \mathrm{~K}$ at identical strain levels [23], as shown in Figure 5. For the metastable $\mathrm{V}_{10} \mathrm{Cr}_{10} \mathrm{Co}_{30} \mathrm{Fe}_{50}$ (at. \%) HEA, the strength increases to nearly $2 \mathrm{GPa}$ at 77 $\mathrm{K}$, which is double of that at $298 \mathrm{~K}$, due to the accelerated martensitic transformation [43]. Besides this, the ductility of metastable $\mathrm{Fe}_{45} \mathrm{Co}_{30} \mathrm{Cr}_{10} \mathrm{~V}_{10} \mathrm{Ni}_{5-x} \mathrm{Mn}_{x}(x=2.5,5)$ (at. \%) HEAs can be deteriorated at $77 \mathrm{~K}$ since the lower SFE triggered by the cryogenic temperature causes more rapid exhaustion of TRIP capability [102].
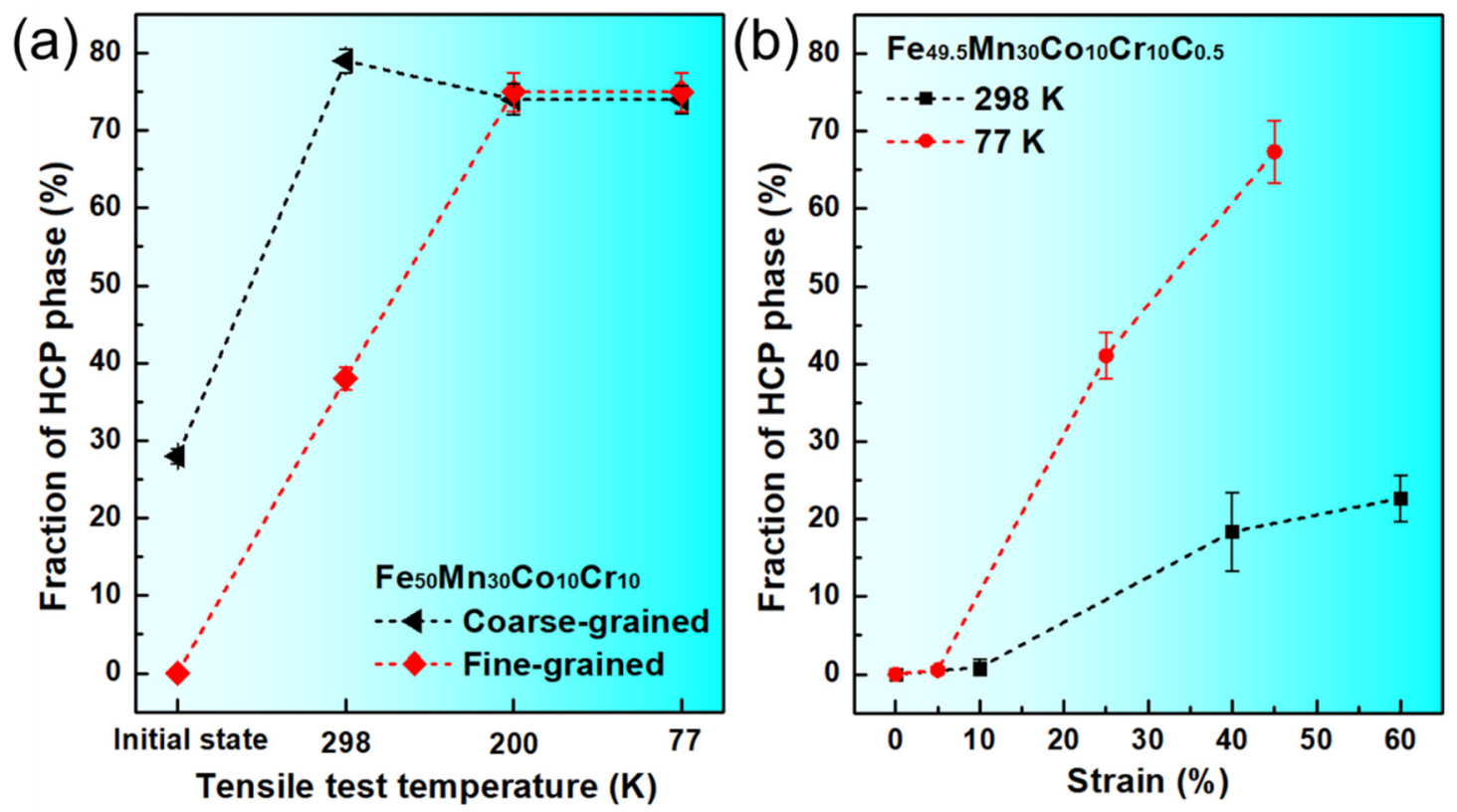

Figure 5. (a) Fractions of HCP phase near fracture surfaces in the coarse-grained and fine-grained $\mathrm{Fe}_{49.5} \mathrm{Mn}_{30} \mathrm{Co}_{10} \mathrm{Cr}_{10}($ at. \%) HEA deformed at $298 \mathrm{~K}, 200 \mathrm{~K}$ and $77 \mathrm{~K}$; (b) Fractions of HCP phase corresponding to different strains in $\mathrm{Fe}_{49.5} \mathrm{Mn}_{30} \mathrm{Co}_{10} \mathrm{Cr}_{10}$ $\mathrm{C}_{0.5}$ (at. \%) HEA tested at $293 \mathrm{~K}$ (local strain) and $77 \mathrm{~K}$ (global strain) based on EBSD analysis [22,23,35].

\subsubsection{High-Temperature Deformation of Metastable HEAs}

It is known that the martensite is relatively stable only at low temperatures, and the displacive martensite transformation usually cannot occur over high temperatures (e.g., $>773 \mathrm{~K}$ ). For example, it has been found that the HCP phase disappears in a cold-rolled $\mathrm{Fe}_{49.5} \mathrm{Mn}_{30} \mathrm{Co}_{10} \mathrm{Cr}_{10} \mathrm{C}_{0.5}$ (at. \%) HEA after tempering at $673 \mathrm{~K}$ [101]. High temperatures facilitate the dislocation movement by supplementing more thermal activation energy; hence, cross-slip of dislocations is promoted and the displacive phase transformation triggered by planar slip is constrained. Although the high-temperature deformation of metastable HEAs has been rarely reported, we could adapt the findings from the traditional TRIP ferrous alloys. For example, the martensite transformation dominates the plastic flows in 304 stainless steel at a lower-temperature regime $(<433 \mathrm{~K})$, while the deformation is mainly governed by dislocation slip at higher temperatures [103].

\subsection{Precipitates-Hardened HEAs}

Most single-phase FCC HEAs possess considerable ductility, but the relatively low yield strength limits their industrial applications. Precipitate hardening has been widely used in ferrous and nonferrous alloys and nano-sized precipitates can efficiently interact with mobile dislocations to significantly enhance the strength of these alloys. Analogously, the strategy of precipitate hardening can also be applied to strengthen the HEAs, e.g., B2 phase [104-107], $\mathrm{L1}_{2}$ structure $\gamma^{\prime}$ phase, Mo-rich $\mu$ and Cr-rich $\sigma$ phases [108-114] have 
been successfully introduced into several HEA systems for achieving higher yield strength by proper annealing treatments at intermediate temperatures. Among these, the $\mathrm{L}_{2}$ phase (e.g., $\mathrm{Ni}_{3}(\mathrm{Al}, \mathrm{Ti})$ ) is a typical precipitate easily generated in the $\mathrm{Al} / \mathrm{Ti}$-doped $\mathrm{CoCrFeMnNi}$ HEA system because of the negative mixing enthalpies among $\mathrm{Ni}, \mathrm{Al}$ and $\mathrm{Ti}$ in favor of the formation of ordered nanoparticles [115]. Upon deformation, precipitates interact with dislocations and retard the slip of dislocations, so the deformation behaviors of precipitateshardened HEAs are different from the precipitates-free HEAs. The characteristics of their deformation at different temperatures are presented below.

\subsubsection{Room-Temperature Deformation of Precipitates-Hardened HEAs}

The interaction behavior between dislocations and precipitates strongly depends on the size of precipitates in alloys. Deformation mechanisms and the corresponding mechanical properties are then affected by the size of precipitates in precipitates-hardened alloys. Generally, when sizes of incoherent particles exceed a critical value, the well-known Orowan mechanism prevails on deformation, and the shearing mechanism will dominate if the precipitates are sufficiently small and coherent with the matrix. He et al. [116] introduced $\mathrm{L}_{2}$ phase into FeCoCrNi-based HEA by adding $\mathrm{Al} / \mathrm{Ti}$ and controlling ageing process, and the strength was increased by $\sim 600 \mathrm{MPa}$ compared to the Al/Ti-free alloy. It is known that the precipitate size depends on the ageing time. Ming et al. [114] aged the $\mathrm{Al}_{0.2} \mathrm{Co}_{1.5} \mathrm{CrFeNi}_{1.5} \mathrm{Ti}_{0.3}$ (at. \%) HEA with different durations. They found that the shearing mechanism prevailed in the sample at the early ageing stage and the Orawan-loop mechanism turned to dominate as the ageing time exceeded $25 \mathrm{~h}$, but the strength of the coarse-grained HEA was almost independent of the ageing time. These findings demonstrate that tailoring the size of precipitates by adjusting aging processing can facilitate the precipitate-dislocation interaction during deformation, which is beneficial to induce good ductility for precipitates-hardened HEAs.

\subsubsection{Cryogenic-Temperature Deformation of Precipitates-Hardened HEAs}

In the 0.2 at. \% Ti-doped equiatomic FeCoCrNi HEA containing nanoprecipitates, extremely low temperatures can lower the SFE of the alloy matrix, whilst the chemical ordering of the $\gamma^{\prime}$ nano-particles has been found to dramatically increase the local energy barrier for twin nucleation, both lead to stacking faulting prevailing at cryogenic temperatures upon deformation [45]. Analogously, the micro-deformation mechanism of the $\mathrm{Co}_{30} \mathrm{Cr}_{15} \mathrm{Ni}_{30} \mathrm{Fe}_{13} \mathrm{Al}_{6} \mathrm{Ti}_{6}$ (at. \%) HEA composed of FCC matrix and $\mathrm{L}_{2}$ precipitates turns from the mechanical twinning to stacking faulting at room or cryogenic temperatures, due to the increase of critical stress for twinning nucleation [46]. Moreover, the low temperature enhances the lattice friction. Consequently, the precipitates-hardened FCC-based HEAs can possess high strength and good ductility at cryogenic temperatures. It should also be noted that the SFE of the matrix will be changed due to the precipitation behavior. Unexpectedly, besides being a hindrance, precipitates sometimes can even play a role in activating phase metastability. For instance, Kwon et al. [117] proposed a precipitation-driven metastability engineering on $\mathrm{Co}_{17.5} \mathrm{Cr}_{12.5} \mathrm{Fe}_{55} \mathrm{Ni}_{10} \mathrm{Mo}_{x} \mathrm{C}_{(5-x)}$ (at. \%) HEAs. The increase of $\mathrm{C}$ content from $1 \%$ to $2 \%$ led to the increase in volume fractions of the carbides from $\sim 5.41 \%$ to $\sim 6.61 \%$, but the displacive phase transformation was enhanced at $77 \mathrm{~K}$ on tension, which was much different from the effect of $\mathrm{C}$ in $\mathrm{Fe}_{50} \mathrm{Mn}_{30} \mathrm{Co}_{10} \mathrm{Cr}_{10} \mathrm{C}_{0.5}$ (at. \%) HEA. The enhanced phase transformation enabled the $2 \% \mathrm{C}$ specimen to have high tensile strength and ductility. However, the phenomenon disappears at room temperature. The relationship among precipitates, the phase metastability and temperature can be further clarified.

\subsubsection{High-Temperature Deformation of Precipitates-Hardened HEAs}

$\mathrm{L1}_{2}$ phase formed in Ni-base alloys plays a significant role to maintain strength at high temperatures. By introducing such nanosize precipitates into the HEA matrix, for instance, $(\mathrm{FeCoNiCr})_{94} \mathrm{Ti}_{2} \mathrm{Al}_{4}$ (at. \%) [118], $\mathrm{Ni}_{45-x}(\mathrm{FeCoCr})_{40}(\mathrm{AlTi})_{15} \mathrm{Hf}_{x}$ (at. \%) [119] and $\mathrm{Ni}_{46} \mathrm{Co}_{23} \mathrm{Cr}_{10} \mathrm{Fe}_{5} \mathrm{Al}_{8.5} \mathrm{Ti}_{4} \mathrm{~W}_{2} \mathrm{Mo}_{1} \mathrm{C}_{0.15} \mathrm{~B}_{0 \cdot 1} \mathrm{Zr}_{0.02}$ (at. \%) [87] HEAs, desirable mechanical 
performance can be attained at elevated temperatures. He et al. [118] systematically studied the flow behavior of a precipitates-hardened (FeCoNiCr) ${ }_{94} \mathrm{Ti}_{2} \mathrm{Al}_{4}$ (at. \%) $\mathrm{HEA}$ in the temperature range from 1023 to $1173 \mathrm{~K}$. At the medium temperature regime (1023$1123 \mathrm{~K})$, the alloy exhibits a high-stress component and activation energy for deformation, because the strengthening induced by nanosized $\gamma^{\prime}$ coherent precipitates still come into play within such temperature regime. As the temperature increases to $1148-1173 \mathrm{~K}$, the $\gamma^{\prime}$ precipitates start to dissolute into the matrix, which facilitates the occurrence of dislocation climb thus decreases stress component and activation energy for dislocation movement.

Precipitates can also help to stabilize the microstructure at high temperatures, which efficiently contributes to inhibiting the high-temperature embrittlement of HEAs. For example, the high-temperature embrittlement of the Cantor alloy can also be alleviated by nano precipitates which can effectively prevent elemental segregation at GBs [19]. For another case, Lu et al. [120] stabilized twins in $\mathrm{Co}_{19.84} \mathrm{Cr}_{19.84} \mathrm{Fe}_{19.84} \mathrm{Mn}_{19.84} \mathrm{Ni}_{19.84} \mathrm{C}_{0.8}$ (at. \%) HEA at high temperatures by introducing nanophases to twin boundaries. More specifically, carbides form along the $9 \mathrm{R}$ phase adjacent to incoherent nanotwin boundaries during the annealing process since the interstitial carbon and substitutional $\mathrm{Cr}$ are prone to enrich at 9R phase boundaries. Then, such elongated interfacial carbides hinder the de-twinning process and thereby stabilize nanotwins at high temperatures. Thus, the strategy overcomes the trade-off between the strength and thermal stability of nanotwinned materials. A similar stabilization effect from carbides was also reported in $\mathrm{Cr}_{24.75} \mathrm{Fe}_{24.75} \mathrm{Co}_{24.75} \mathrm{Ni}_{24.75} \mathrm{Nb}_{0.5} \mathrm{C}_{0.5}$ HEA deformed at a temperature range from 673 to $1073 \mathrm{~K}$ [121]. Carbides provide a significant strengthening effect thus the strength is double that of the equiatomic $\mathrm{FeNiCoCr}$ HEA at that temperature regime. Moreover, carbides can be employed to suppress the nucleation of micro-voids and cracks by reducing the GB sliding and acting as barriers against crack propagation at high temperatures [121]. In addition, Yang et al. [122] employed a duplex-ageing process on $\mathrm{Ni}_{29.9} \mathrm{Co}_{30} \mathrm{Fe}_{13} \mathrm{Cr}_{15} \mathrm{Al}_{6} \mathrm{Ti}_{6} \mathrm{~B}_{0.1}$ (at. \%) alloy, which promoted the transformation from $\mathrm{L1}_{2}$ phase to Heusler phase at GBs; thus, the embrittling intergranular heterostructures can be greatly eliminated, leading to a distinct brittle-to-ductile transition at $973 \mathrm{~K}$ as well as an increase of the tensile strength up to $1 \mathrm{GPa}$.

\subsection{Multiphase HEAs}

In this review, the multiphase HEAs refer to the HEAs consisting of two or more phases that are different in structure and composition. In general, the hard phases contribute to the strength and the soft phases ensure ductility. The temperature-dependent deformation behaviors of multiphase HEAs are associated with the characteristics of the contained phases, and thus are quite different from that of other HEAs.

\subsubsection{Room-Temperature Deformation of Multiphase HEAs}

In multiphase HEAs, strain partitioning does occur among different phases upon deformation. For instance, by using the digital image correlation (DIC) method, it has been found that the soft FCC phase can sustain much higher local strain at a low global strain ( 2\%) compared with the hard BCC/B2 phase in $\mathrm{Al}_{0.5} \mathrm{CoCrFeNi}$ (at. \%) HEA [123]. However, this strain partitioning behavior turns to trail off with increasing the total strain (almost disappear at $\sim 24 \%$ ), and then strain concentration can occur in the vicinity of interphase boundaries, leading to the formation of cracks at the interfaces upon deformation at room temperature $[47,124]$, as schematically shown in Figure 6. 


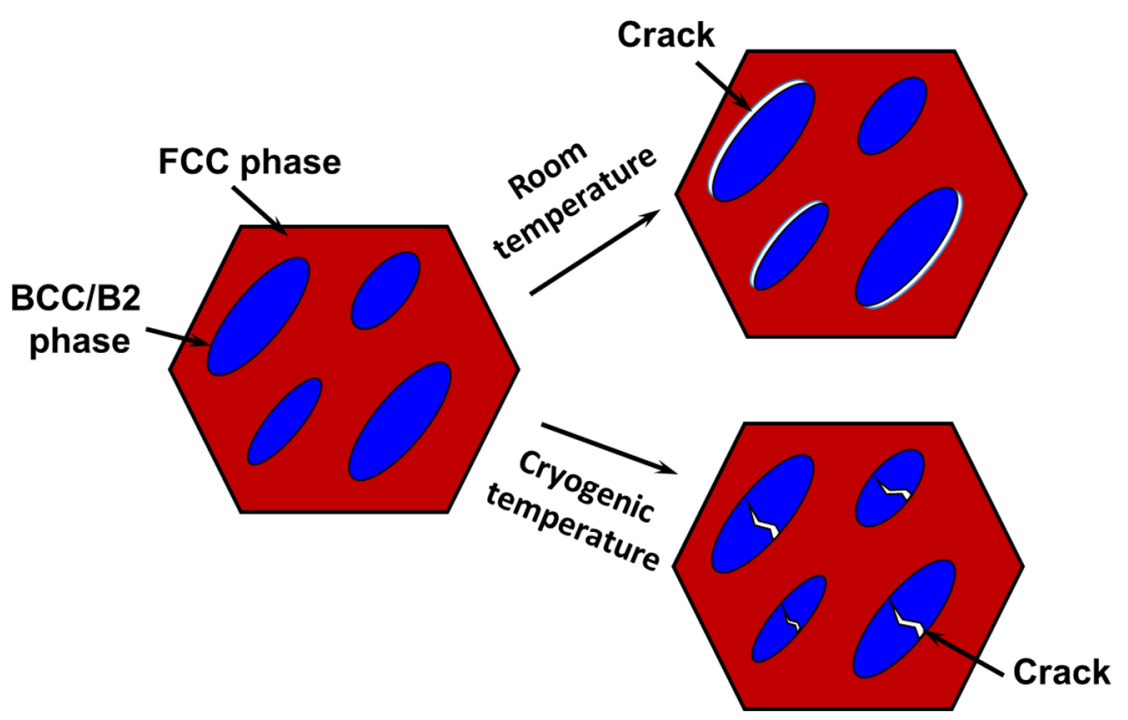

Figure 6. Schematics showing the fracture modes of multiphase HEAs at room and cryogenic temperatures.

In $\mathrm{AlCoCrFeNi}{ }_{2.1}$ (at. \%) eutectic HEA (EHEA), the $\mathrm{L}_{2}$ phase is deformed in the manner of planar dislocation slip, with a slip system of $\{111\}<110>$, and stacking faults due to the low SFE, contributing to the high strain hardening and ductility [48]. On the other hand, dislocations glide in B2 phase and the Cr-rich precipitates can further strengthen the B2 phase, contributing to the high strength of the material. Therefore, the as-cast $\mathrm{AlCoCrFeNi}_{2.1}$ (at. \%) EHEA exhibits high strength and decent ductility [48]. Besides this, the spatial configuration of multiple phases is supposed to significantly affect the mechanical properties of multiphase HEAs. As illustrated in Figure 7a, the disorder distribution of $\mathrm{B} 2$ phase in the $\mathrm{L}_{2}$ matrix of the as-cast $\mathrm{AlCoCrFeNi}_{2.1}$ (at. \%) EHEA is hard to enable good work hardening on deformation. With the well-tuned distribution of the phases by thermal-mechanical treatments, the mechanical properties of multiphase HEAs can be greatly improved by altering the deformation mechanisms. For instance, as illustrated in Figure $7 \mathrm{~b}, \mathrm{AlCoCrFeNi}{ }_{2.1}$ (at. \%) EHEA with dual-phase heterogeneous lamella (DPHL) structure achieves a superior strength-ductility combination, due to the self-generated microcrack-arresting mechanism originated from the DPHL structure [125]. Further, the $\mathrm{Al}_{19} \mathrm{Co}_{20} \mathrm{Fe}_{20} \mathrm{Ni}_{41}$ (at. \%) EHEA obtained through discarding $\mathrm{Cr}$ in $\mathrm{AlCoCrFeNi}{ }_{2.1}$ (at. \%) EHEA shows heterogeneous lamella microstructure (similar to that in the schematic diagram of Figure $7 \mathrm{~b}$ but the size of grains is in nanoscale) after thermo-mechanical treatment. Such special microstructure stimulates a sequential activation of stress-dependent multi-type twinning mechanisms upon deformation [49]. As a consequence, the alloy exhibits multistage work hardening and attains a more desirable strength-ductility synergy than that of DPHL EHEA. Further, a hierarchically organized herringbone structure is generated in $\mathrm{Al}_{19} \mathrm{Co}_{20} \mathrm{Fe}_{20} \mathrm{Ni}_{41}$ (at. \%) EHEA by directional solidification, which efficiently renders special hierarchical buffering by adjacent dynamic strain-hardened features, then strongly prevents the catastrophic growth and percolation of microcracks, as schematically shown in Figure 7c. The self-buffering herringbone alloy shows a high uniform tensile elongation ( $50 \%)$ much higher than the conventional nonbuffering EHEAs ( 16\%) but without sacrificing strength [50]. 
(a)

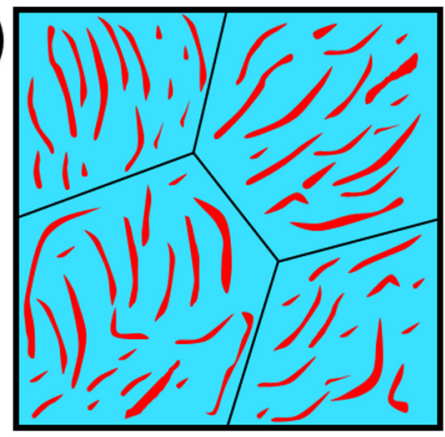

Cast EHEA (b)

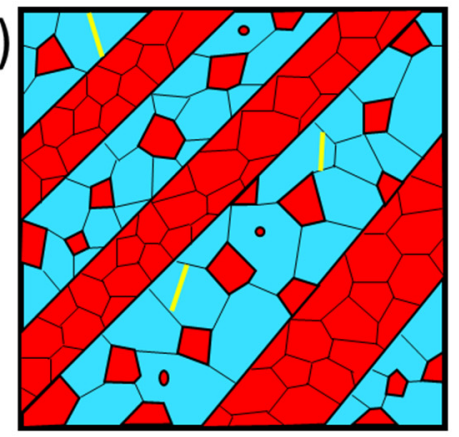

DPHL EHEA
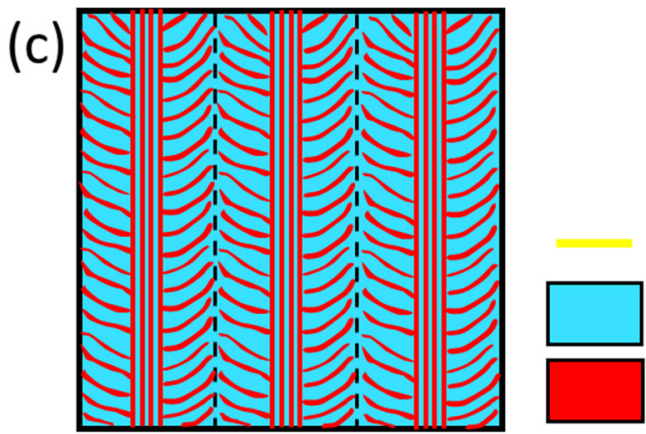

AT

$\mathrm{L1}_{2}$

B2

Figure 7. Schematics showing the microstructural characteristics of (a) cast EHEA, (b) DPHL EHEA and (c) herringbone EHEA. 'AT' refers to the annealing twin.

In addition, the strategy of crystal-glass dual-phase configuration has been also employed in the design of high-entropy materials [126]. The metallic glass phase of such nanocomposites can efficiently absorb and emit dislocations to prevent the formation of pile-up configurations, which alleviates the local strain localization and promotes homogenous plastic flow on deformation. Therefore, this nanocomposite owns a nearly ideal strength concurrently with remarkable deformability at room temperature. This strategy also provides a promising path to the further design of ultrastrong and ductile metallic materials in the future.

\subsubsection{Cryogenic-Temperature Deformation of Multiphase HEAs}

In general, the strength of multiphase HEAs increases with lowering the deformation temperature but the ductility is not prominently enhanced. Dislocation movement in BCC phase is more difficult at cryogenic temperatures but FCC phase becomes more deformable; thus, the plastic compatibility between the constituent phases can be degraded. For example, Park et al. [47] found that the geometrical necessary dislocations (GND) density in FCC phase was much higher than that of $\mathrm{BCC}$ phase when the $\mathrm{Al}_{0.5} \mathrm{CoCrFeMnNi}$ (at. \%) HEA was deformed at cryogenic temperatures. High back stress induced by the profuse GND in FCC phase provides an additional strengthening mechanism and improves the uniform deformation, which can alleviate the formation of micro-void and growth. However, the hard and brittle BCC phase could not withstand the strain and then break, as schematically shown in Figure 6. Therefore, the alloy displays a slightly higher uniform elongation at cryogenic deformation in comparison with that at room temperature, but it fractures suddenly on tension without the necking stage. The behaviors showed in this typical case could also be adapted in dual-phase AlCoCrFeNi 2.1 (at. \%) EHEA [127-129].

\subsubsection{High-Temperature Deformation of Multiphase HEAs}

At elevated temperatures, the multiphase structure may reorganize via recrystallization, and precipitates are probably generated from the initial phases, leading to a change in the fractions of phases. For example, the fraction of $\mathrm{B} 2$ phase surpasses that of $\mathrm{L}_{2}$ phase after high-temperature deformation through dynamic recrystallization in $\mathrm{AlCoCrFeNi}{ }_{2.1}$ (at. \%) EHEA [130]. During the dynamic recrystallization process, nano-sized B2 $2_{\text {II }}$ phases formed in $\mathrm{L}_{2}$ phase retard recrystallization and provide a strengthening effect, and recrystallization of the $\mathrm{L}_{2}$ matrix makes a significant contribution to the softening process by reducing the strain localization. Therefore, the strength of the alloy ( $55 \mathrm{MPa})$ is maintained and the elongation is over $240 \%$ upon tension at $1273 \mathrm{~K}$. Strain softening associated with the formation of a heterogeneous necklace microstructure via dynamic recrystallization is also found in an annealed $\mathrm{TaMo}_{0.5} \mathrm{ZrTi}_{1.5} \mathrm{Al}_{0.1} \mathrm{Si}_{0.2}$ (at. \%) HEA when subjected to compression at $1273 \mathrm{~K}$ [131]. Further, dynamic precipitation strengthening effect is observed in a CoCrFeNiTa EHEA, i.e., the high-temperature precipitation of two kinds 
of nanoprecipitates ( $\mathrm{L}_{2}$ ordered and $\mathrm{Ni}_{3} \mathrm{Ta}$ type) in the FCC-solution phase extends the applicable temperature range of the material [132], which also provides a useful insight for designing high-performance alloys for high-temperature applications.

\section{Summary and Outlook}

This article reviews the temperature-dependent deformation behaviors and the corresponding microscale mechanisms of various HEAs. Figure 8 outlines the main contents which can be summarized below.

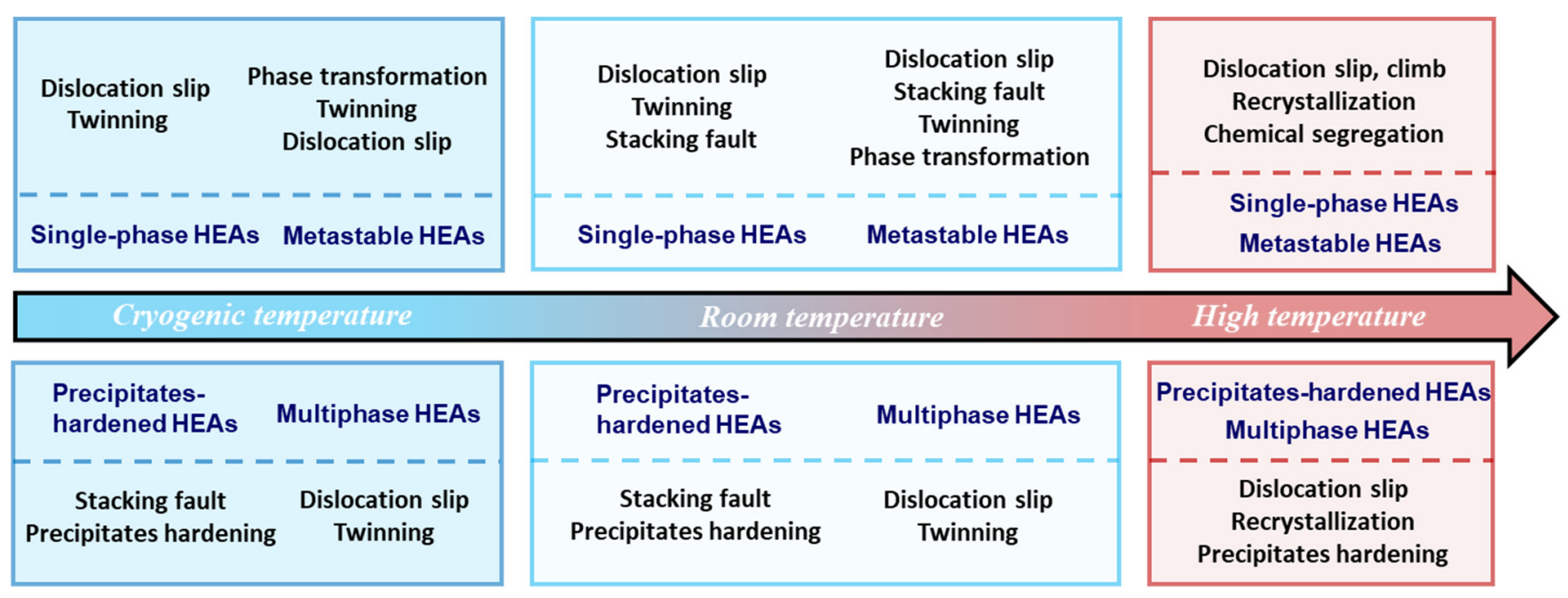

Figure 8. Summary of the microscale mechanisms for the deformation of typical HEAs at different temperatures.

1. At room temperature, dislocation slip, mechanical twinning and stacking faulting can prevail to dominate the plasticity of different FCC structured HEAs, dependent on the chemical composition. Displacive phase transformation plays a key role during plastic deformation of metastable HEAs. Dislocation slip is the main way to accommodate the deformation in BCC structured HEAs, and phase transformation can also occur in a few cases. In precipitates-hardened FCC HEAs, the nanoprecipitates enhance the strength but usually deteriorate the ductility of HEAs, mechanisms of dislocation slip and stacking faulting in the matrix can still contribute to a decent ductility, and tailoring the size of precipitates by adjusting aging processing can tune the precipitatedislocation interaction mechanism. In FCC-BCC multiphase HEAs, the soft FCC phase contributes more to the ductility through dislocation slip or mechanical twinning and the hard BCC phase provides a hardening effect. Moreover, numerous investigations have suggested that tuning the microstructure via specific processes is an efficient way to optimize the mechanical properties of HEAs.

2. As decreasing temperature to the cryogenic regime, SFE of FCC HEAs accordingly decreases and the lattice friction increases. Hence, the strength is improved, and the propensity of mechanical twinning, stacking faulting and phase transformation get enhanced. Therefore, the strength and ductility as well as toughness of single-phase or precipitates-hardened FCC structured HEAs get improved. For the FCC HEAs, cryogenic processing can be a good way to enhance formability. For the metastable HEAs, the promoted phase transformation resulted by cryogenic temperatures contributes to higher ultimate strength, but the ductility is not always improved since the phase transformation can be completed at earlier deformation stages compared to that at room temperature. Moreover, since FCC phase still exhibits a considerable strain hardening capability but BCC phase turns brittle at cryogenic temperatures, the strength of multiphase HEAs can be further enhanced but the ductility is hardly improved. 
3. Under high-temperature deformation, dislocation activities of HEAs are promoted, e.g., cross-slip, climb, annihilation, recovery and recrystallization. TWIP/TRIP effects are suppressed in the metastable HEAs at high temperatures, which leads to the ductility decrease. Elemental segregation in single-phase HEAs also results in hightemperature embrittlement. To alleviate the embrittlement, pre-formed precipitates can be employed to maintain the mechanical and phase stability of HEAs, i.e., introducing additional phases to decorate grain boundaries can be an accessible method to optimize the mechanical performance of HEAs at high temperatures.

Overall, various HEAs display good mechanical properties in a wide range of temperatures and thus show great potential to be applied to harsh conditions. Moreover, the various strengthening and toughening strategies are worthy of being adapted in future alloys, including designing hierarchical microstructures and introducing nanophases alleviating high-temperature embrittlement. On the premise of tuning the above various microscale mechanisms, it is greatly possible to develop more HEAs with the combination of desirable mechanical properties and other functional properties, e.g., resistance to corrosion $[13,15,133]$ and hydrogen-embrittlement $[15,134,135]$, magnetic $[11,12,136]$, thermal expansion $[137,138]$ and electrical properties [139-141], which will render the novel HEAs more powerful and attractive for practical applications.

Author Contributions: Conceptualization, P.W., K.G., D.Y. and Z.L.; data curation, P.W., K.G., D.Y. and Z.L.; writing—original draft preparation, P.W., K.G., D.Y. and Z.L.; writing—review and editing, K.G., D.Y. and Z.L. All authors have read and agreed to the published version of the manuscript.

Funding: This work was funded by the Natural Science Foundation of Hunan province (grant numbers "2021JJ10056 and 2021JJ40736"), the National Natural Science Foundation of China (grant numbers "51971248 and 52101166"), the Special Funding for the Construction of Innovative Hunan Province of China (grant number "2019RS1001") and the Fundamental Research Funds for the Central Universities of Central South University (Grant No. 2020zzts072).

Institutional Review Board Statement: Not applicable.

Informed Consent Statement: Not applicable.

Data Availability Statement: No new data were created or analyzed in this study. Data sharing is not applicable to this article.

Conflicts of Interest: The authors declare no conflict of interest.

\section{References}

1. Yeh, J.-W.; Chen, S.K.; Lin, S.-J.; Gan, J.-Y.; Chin, T.-S.; Shun, T.-T.; Tsau, C.-H.; Chang, S.-Y. Nanostructured High-Entropy Alloys with Multiple Principal Elements: Novel Alloy Design Concepts and Outcomes. Adv. Eng. Mater. 2004, 6, 299-303. [CrossRef]

2. Li, Z.; Raabe, D. Strong and Ductile Non-equiatomic High-Entropy Alloys: Design, Processing, Microstructure, and Mechanical Properties. JOM 2017, 69, 2099-2106. [CrossRef]

3. Chen, J.; Niu, P.; Liu, Y.; Lu, Y.; Wang, X.; Peng, Y.; Liu, J. Effect of Zr content on microstructure and mechanical properties of AlCoCrFeNi high entropy alloy. Mater. Des. 2016, 94, 39-44. [CrossRef]

4. Cheng, K.-H.; Lai, C.-H.; Lin, S.-J.; Yeh, J.-W. Structural and mechanical properties of multi-element (AlCrMoTaTiZr)N $\mathrm{N}_{\mathrm{x}}$ coatings by reactive magnetron sputtering. Thin Solid Films 2011, 519, 3185-3190. [CrossRef]

5. Chen, Y.; Duval, T.; Hung, U.; Yeh, J.; Shih, H. Microstructure and electrochemical properties of high entropy alloys-a comparison with type-304 stainless steel. Corros. Sci. 2005, 47, 2257-2279. [CrossRef]

6. Quiambao, K.F.; McDonnell, S.J.; Schreiber, D.K.; Gerard, A.Y.; Freedy, K.M.; Lu, P.; Saal, J.E.; Frankel, G.S.; Scully, J.R. Passivation of a corrosion resistant high entropy alloy in non-oxidizing sulfate solutions. Acta Mater. 2019, 164, 362-376. [CrossRef]

7. Fu, Z.; Yang, B.; Gan, K.; Yan, D.; Li, Z.; Gou, G.; Chen, H.; Wang, Z. Improving the hydrogen embrittlement resistance of a selective laser melted high-entropy alloy via modifying the cellular structures. Corros. Sci. 2021, 190, 109695. [CrossRef]

8. Kumar, N.; Fusco, M.; Komarasamy, M.; Mishra, R.; Bourham, M.; Murty, K. Understanding effect of 3.5 wt.\% NaCl on the corrosion of Al0.1CoCrFeNi high-entropy alloy. J. Nucl. Mater. 2017, 495, 154-163. [CrossRef]

9. Senkov, O.; Scott, J.M.; Senkova, S.V.; Meisenkothen, F.; Miracle, D.B.; Woodward, C.F. Microstructure and elevated temperature properties of a refractory TaNbHfZrTi alloy. J. Mater. Sci. 2012, 47, 4062-4074. [CrossRef]

10. Chuang, M.-H.; Tsai, M.-H.; Wang, W.-R.; Lin, S.-J.; Yeh, J.-W. Microstructure and wear behavior of AlxCo1.5CrFeNi1.5Tiy high-entropy alloys. Acta Mater. 2011, 59, 6308-6317. [CrossRef] 
11. Han, L.; Rao, Z.; Filho, I.R.S.; Maccari, F.; Wei, Y.; Wu, G.; Ahmadian, A.; Zhou, X.; Gutfleisch, O.; Ponge, D.; et al. Ultrastrong and Ductile Soft Magnetic High-Entropy Alloys via Coherent Ordered Nanoprecipitates. Adv. Mater. 2021, 33, 2102139. [CrossRef]

12. Rao, Z.; Dutta, B.; Körmann, F.; Lu, W.; Zhou, X.; Liu, C.; da Silva, A.K.; Wiedwald, U.; Spasova, M.; Farle, M.; et al. Beyond Solid Solution High-Entropy Alloys: Tailoring Magnetic Properties via Spinodal Decomposition. Adv. Funct. Mater. 2021, 31, 2007668. [CrossRef]

13. Wu, P.; Gan, K.; Yan, D.; Fu, Z.; Li, Z. A non-equiatomic FeNiCoCr high-entropy alloy with excellent anti-corrosion performance and strength-ductility synergy. Corros. Sci. 2021, 183, 109341. [CrossRef]

14. Li, Z.; Pradeep, K.G.; Deng, Y.; Raabe, D.; Tasan, C.C. Metastable high-entropy dual-phase alloys overcome the strength-ductility trade-off. Nat. Cell Biol. 2016, 534, 227-230. [CrossRef]

15. Luo, H.; Sohn, S.S.; Lu, W.; Li, L.; Li, X.; Soundararajan, C.K.; Krieger, W.; Li, Z.; Raabe, D. A strong and ductile medium-entropy alloy resists hydrogen embrittlement and corrosion. Nat. Commun. 2020, 11, 3081. [CrossRef]

16. Nene, S.; Frank, M.; Liu, K.; Sinha, S.; Mishra, R.; McWilliams, B.; Cho, K. Corrosion-resistant high entropy alloy with high strength and ductility. Scr. Mater. 2019, 166, 168-172. [CrossRef]

17. Messerschmidt, U. Dislocation Dynamics During Plastic Deformation; Springer: Berlin/Heidelberg, Germany, 2010.

18. Otto, F.; Dlouhý, A.; Somsen, C.; Bei, H.; Eggeler, G.; George, E.P. The influences of temperature and microstructure on the tensile properties of a CoCrFeMnNi high-entropy alloy. Acta Mater. 2013, 61, 5743-5755. [CrossRef]

19. Ming, K.; Li, L.; Li, Z.; Bi, X.; Wang, J. Grain boundary decohesion by nanoclustering Ni and Cr separately in CrMnFeCoNi high-entropy alloys. Sci. Adv. 2019, 5, eaay0639. [CrossRef]

20. Yang, T.; Tang, Z.; Xie, X.; Carroll, R.; Wang, G.; Wang, Y.; Dahmen, K.A.; Liaw, P.K.; Zhang, Y. Deformation mechanisms of $\mathrm{Al}_{0.1} \mathrm{CoCrFeNi}$ at elevated temperatures. Mater. Sci. Eng. A 2017, 684, 552-558. [CrossRef]

21. Xia, S.; Zhang, Y. Deformation mechanisms of Al0.1CoCrFeNi high entropy alloy at ambient and cryogenic temperatures. Mater. Sci. Eng. A 2018, 733, 408-413. [CrossRef]

22. Li, D.; Li, Z.; Xie, L.; Zhang, Y.; Wang, W. Cryogenic mechanical behavior of a TRIP-assisted dual-phase high-entropy alloy. Nano Res. 2021, 1-8. [CrossRef]

23. Wang, Z.; Lu, W.; Raabe, D.; Li, Z. On the mechanism of extraordinary strain hardening in an interstitial high-entropy alloy under cryogenic conditions. J. Alloys Compd. 2019, 781, 734-743. [CrossRef]

24. Hull, D.; Bacon, D. Introduction to Dislocations; Elsevier: Amsterdam, The Netherlands, 2011.

25. Chowdhury, P.; Canadinc, D.; Sehitoglu, H. On deformation behavior of Fe-Mn based structural alloys. Mater. Sci. Eng. R. Rep. 2017, 122, 1-28. [CrossRef]

26. Hirth, J.O. Thermodynamics of stacking faults. Mater. Trans. 1970, 1, 2367-2374.

27. Anderson, P.M.; Hirth, J.P.; Lothe, J. Theory of Dislocations; Cambridge University Press: Cambridge, UK, 2017.

28. Gottstein, G. Physical Foundations of Materials Science; Springer Science \& Business Media: Berlin/Heidelberg, Germany, 2013.

29. Sherby, O.D.; Burke, P.M. Mechanical behavior of crystalline solids at elevated temperature. Prog. Mater. Sci. 1968, 13, 323-390. [CrossRef]

30. Mohamed, F.A.; Langdon, T.G. The transition from dislocation climb to viscous glide in creep of solid solution alloys. Acta Metall. 1974, 22, 779-788. [CrossRef]

31. Yao, M.; Pradeep, K.; Tasan, C.; Raabe, D. A novel, single phase, non-equiatomic FeMnNiCoCr high-entropy alloy with exceptional phase stability and tensile ductility. Scr. Mater. 2014, 72-73, 5-8. [CrossRef]

32. Deng, Y.; Tasan, C.; Pradeep, K.; Springer, H.; Kostka, A.; Raabe, D. Design of a twinning-induced plasticity high entropy alloy. Acta Mater. 2015, 94, 124-133. [CrossRef]

33. Yang, Z.; Yan, D.; Lu, W.; Li, Z. A TWIP-TRIP quinary high-entropy alloy: Tuning phase stability and microstructure for enhanced mechanical properties. Mater. Sci. Eng. A 2021, 801, 140441. [CrossRef]

34. Li, Z.; Tasan, C.C.; Pradeep, K.G.; Raabe, D. A TRIP-assisted dual-phase high-entropy alloy: Grain size and phase fraction effects on deformation behavior. Acta Mater. 2017, 131, 323-335. [CrossRef]

35. Li, Z.; Tasan, C.C.; Springer, H.; Gault, B.; Raabe, D. Interstitial atoms enable joint twinning and transformation induced plasticity in strong and ductile high-entropy alloys. Sci. Rep. 2017, 7, 40704. [CrossRef]

36. He, Z.; Jia, N.; Ma, D.; Yan, H.; Li, Z.; Raabe, D. Joint contribution of transformation and twinning to the high strength-ductility combination of a FeMnCoCr high entropy alloy at cryogenic temperatures. Mater. Sci. Eng. A 2019, 759, 437-447. [CrossRef]

37. Wang, Y.; Liu, B.; Yan, K.; Wang, M.; Kabra, S.; Chiu, Y.L.; Dye, D.; Lee, P.D.; Liu, Y.; Cai, B. Probing deformation mechanisms of a FeCoCrNi high-entropy alloy at 293 and $77 \mathrm{~K}$ using in situ neutron diffraction. Acta Mater. 2018, 154, 79-89. [CrossRef]

38. Seol, J.B.; Bae, J.W.; Li, Z.; Han, J.C.; Kim, J.G.; Raabe, D.; Kim, H.S. Boron doped ultrastrong and ductile high-entropy alloys. Acta Mater. 2018, 151, 366-376. [CrossRef]

39. Li, Z. Interstitial equiatomic CoCrFeMnNi high-entropy alloys: Carbon content, microstructure, and compositional homogeneity effects on deformation behavior. Acta Mater. 2019, 164, 400-412. [CrossRef]

40. Guo, W.; Su, J.; Lu, W.; Liebscher, C.H.; Kirchlechner, C.; Ikeda, Y.; Körmann, F.; Liu, X.; Xue, Y.; Dehm, G. Dislocation-induced breakthrough of strength and ductility trade-off in a non-equiatomic high-entropy alloy. Acta Mater. 2020, 185, 45-54. [CrossRef]

41. Lei, Z.; Liu, X.; Wu, Y.; Wang, H.; Jiang, S.; Wang, S.; Hui, X.; Wu, Y.; Gault, B.; Kontis, P.; et al. Enhanced strength and ductility in a high-entropy alloy via ordered oxygen complexes. Nat. Cell Biol. 2018, 563, 546-550. [CrossRef] 
42. Wang, S.; Wu, M.; Shu, D.; Zhu, G.; Wang, D.; Sun, B. Mechanical instability and tensile properties of TiZrHfNbTa high entropy alloy at cryogenic temperatures. Acta Mater. 2020, 201, 517-527. [CrossRef]

43. Kim, D.G.; Jo, Y.H.; Yang, J.; Choi, W.-M.; Kim, H.S.; Lee, B.-J.; Sohn, S.S.; Lee, S. Ultrastrong duplex high-entropy alloy with 2 GPa cryogenic strength enabled by an accelerated martensitic transformation. Scr. Mater. 2019, 171, 67-72. [CrossRef]

44. Huang, H.; Wu, Y.; He, J.; Wang, H.; Liu, X.; An, K.; Wu, W.; Lu, Z. Phase-Transformation Ductilization of Brittle High-Entropy Alloys via Metastability Engineering. Adv. Mater. 2017, 29, 7. [CrossRef] [PubMed]

45. Tong, Y.; Chen, D.; Han, B.; Wang, J.; Feng, R.; Yang, T.; Zhao, C.; Zhao, Y.; Guo, W.; Shimizu, Y.; et al. Outstanding tensile properties of a precipitation-strengthened FeCoNiCrTi0.2 high-entropy alloy at room and cryogenic temperatures. Acta Mater. 2019, 165, 228-240. [CrossRef]

46. Yang, T.; Zhao, Y.; Luan, J.; Han, B.; Wei, J.; Kai, J.; Liu, C. Nanoparticles-strengthened high-entropy alloys for cryogenic applications showing an exceptional strength-ductility synergy. Scr. Mater. 2019, 164, 30-35. [CrossRef]

47. Park, J.M.; Moon, J.; Bae, J.W.; Kim, D.H.; Jo, Y.H.; Lee, S.; Kim, H.S. Role of BCC phase on tensile behavior of dual-phase $\mathrm{Al}_{0.5} \mathrm{CoCrFeMnNi}$ high-entropy alloy at cryogenic temperature. Mater. Sci. Eng. A 2019, 746, 443-447. [CrossRef]

48. Gao, X.; Lu, Y.; Zhang, B.; Liang, N.; Wu, G.; Sha, G.; Liu, J.; Zhao, Y. Microstructural origins of high strength and high ductility in an $\mathrm{AlCoCrFeNi}{ }_{2.1}$ eutectic high-entropy alloy. Acta Mater. 2017, 141, 59-66. [CrossRef]

49. Shi, P.; Zhong, Y.; Li, Y.; Ren, W.; Zheng, T.; Shen, Z.; Yang, B.; Peng, J.; Hu, P.; Zhang, Y.; et al. Multistage work hardening assisted by multi-type twinning in ultrafine-grained heterostructural eutectic high-entropy alloys. Mater. Today 2020, 41, 62-71. [CrossRef]

50. Shi, P.; Li, R.; Li, Y.; Wen, Y.; Zhong, Y.; Ren, W.; Shen, Z.; Zheng, T.; Peng, J.; Liang, X.; et al. Hierarchical crack buffering triples ductility in eutectic herringbone high-entropy alloys. Science 2021, 373, 912-918. [CrossRef]

51. Cantor, B.; Chang, I.T.H.; Knight, P.; Vincent, A.J.B. Microstructural development in equiatomic multicomponent alloys. Mater. Sci. Eng. A 2004, 375-377, 213-218. [CrossRef]

52. Laplanche, G.; Kostka, A.; Horst, O.M.; Eggeler, G.; George, E.P. Microstructure evolution and critical stress for twinning in the CrMnFeCoNi high-entropy alloy. Acta Mater. 2016, 118, 152-163. [CrossRef]

53. Wu, X.; Mayweg, D.; Ponge, D.; Li, Z. Microstructure and deformation behavior of two TWIP/TRIP high entropy alloys upon grain refinement. Mater. Sci. Eng. A 2021, 802, 140661. [CrossRef]

54. Owen, L.; Pickering, E.; Playford, H.; Stone, H.; Tucker, M.; Jones, N. An assessment of the lattice strain in the CrMnFeCoNi high-entropy alloy. Acta Mater. 2017, 122, 11-18. [CrossRef]

55. Thirathipviwat, P.; Sato, S.; Song, G.; Bednarcik, J.; Nielsch, K.; Han, J. Compositional complexity dependence of lattice distortion in FeNiCoCrMn high entropy alloy system. Mater. Sci. Eng. A 2021, 823, 141775. [CrossRef]

56. Wang, Z.; Baker, I.; Cai, Z.; Chen, S.; Poplawsky, J.; Guo, W. The effect of interstitial carbon on the mechanical properties and dislocation substructure evolution in $\mathrm{Fe}_{40.4} \mathrm{Ni}_{11.3} \mathrm{Mn}_{34.8} \mathrm{Al}_{7.5} \mathrm{Cr}_{6}$ high entropy alloys. Acta Mater. 2016, 120, 228-239. [CrossRef]

57. Wu, Z.; Parish, C.; Bei, H. Nano-twin mediated plasticity in carbon-containing FeNiCoCrMn high entropy alloys. J. Alloys Compd. 2015, 647, 815-822. [CrossRef]

58. Jodi, D.E.; Park, J.; Park, N. Strengthening of ultrafine-grained equiatomic CoCrFeMnNi high-entropy alloy by nitrogen addition. Mater. Lett. 2020, 258, 126772. [CrossRef]

59. Seol, J.B.; Bae, J.W.; Kim, J.G.; Sung, H.; Li, Z.; Lee, H.H.; Shim, S.H.; Jang, J.H.; Ko, W.-S.; Hong, S.I.; et al. Short-range order strengthening in boron-doped high-entropy alloys for cryogenic applications. Acta Mater. 2020, 194, 366-377. [CrossRef]

60. Hirth, J.P.; Cohen, M. On the strength-differential phenomenon in hardened steel. Mater. Trans. 1970, 1, 3-8.

61. Reed, R.P. Nitrogen in austenitic stainless steels. JOM 1989, 41, 16-21. [CrossRef]

62. Ikeda, Y.; Tanaka, I.; Neugebauer, J.; Körmann, F. Impact of interstitial C on phase stability and stacking-fault energy of the CrMnFeCoNi high-entropy alloy. Phys. Rev. Mater. 2019, 3, 113603. [CrossRef]

63. Senkov, O.N.; Wilks, G.B.; Scott, J.M.; Miracle, D.B. Mechanical properties of NbMoTaW and VNbMoTaW refractory high entropy alloys. Intermetallics 2011, 19, 698-706. [CrossRef]

64. Wu, Y.; Cai, Y.; Wang, T.; Si, J.; Zhu, J.; Wang, Y.; Hui, X. A refractory Hf25Nb25Ti25Zr25 high-entropy alloy with excellent structural stability and tensile properties. Mater. Lett. 2014, 130, 277-280. [CrossRef]

65. Zou, Y.; Maiti, S.; Steurer, W.; Spolenak, R. Size-dependent plasticity in an Nb25Mo25Ta25W25 refractory high-entropy alloy. Acta Mater. 2014, 65, 85-97. [CrossRef]

66. Schuh, B.; Völker, B.; Todt, J.; Schell, N.; Perrière, L.; Li, J.; Couzinie, J.-P.; Hohenwarter, A. Thermodynamic instability of a nanocrystalline, single-phase TiZrNbHfTa alloy and its impact on the mechanical properties. Acta Mater. 2018, 142, $201-212$. [CrossRef]

67. Dirras, G.; Lilensten, L.; Djemia, P.; Laurent-Brocq, M.; Tingaud, D.; Couzinie, J.-P.; Perrière, L.; Chauveau, T.; Guillot, I. Elastic and plastic properties of as-cast equimolar TiHfZrTaNb high-entropy alloy. Mater. Sci. Eng. A 2016, 654, 30-38. [CrossRef]

68. Senkov, O.; Scott, J.; Senkova, S.; Miracle, D.; Woodward, C.; Senkov, O.; Scott, J.; Senkova, S.; Miracle, D.; Woodward, C. Microstructure and room temperature properties of a high-entropy TaNbHfZrTi alloy. J. Alloys Compd. 2011, 509, 6043-6048. [CrossRef]

69. Lilensten, L.; Couzinié, J.-P.; Perrière, L.; Hocini, A.; Keller, C.; Dirras, G.; Guillot, I. Study of a bcc multi-principal element alloy: Tensile and simple shear properties and underlying deformation mechanisms. Acta Mater. 2018, 142, 131-141. [CrossRef]

70. Couzinie, J.-P.; Lilensten, L.; Champion, Y.; Dirras, G.; Perrière, L.; Guillot, I. On the room temperature deformation mechanisms of a TiZrHfNbTa refractory high-entropy alloy. Mater. Sci. Eng. A 2015, 645, 255-263. [CrossRef] 
71. Bu, Y.; Li, Z.; Liu, J.; Wang, H.; Raabe, D.; Yang, W. Nonbasal Slip Systems Enable a Strong and Ductile Hexagonal-Close-Packed High-Entropy Phase. Phys. Rev. Lett. 2019, 122, 075502. [CrossRef]

72. François, D.; Pineau, A.; Zaoui, A. Mechanical Behaviour of Materials; Springer Science \& Business Media: Amsterdam, The Netherlands, 1980.

73. Huang, S.; Li, W.; Lu, S.; Tian, F.; Shen, J.; Holmstrom, E.; Vitos, L. Temperature dependent stacking fault energy of FeCrCoNiMn high entropy alloy. Scr. Mater. 2015, 108, 44-47. [CrossRef]

74. Bönisch, M.; Wu, Y.; Sehitoglu, H. Hardening by slip-twin and twin-twin interactions in FeMnNiCoCr. Acta Mater. 2018, 153, 391-403. [CrossRef]

75. Gludovatz, B.; Hohenwarter, A.; Catoor, D.; Chang, E.H.; George, E.P.; Ritchie, R.O. A fracture-resistant high-entropy alloy for cryogenic applications. Science 2014, 345, 1153-1158. [CrossRef]

76. Chen, L.; Wei, R.; Tang, K.; Zhang, J.; Jiang, F.; Sun, J. Ductile-brittle transition of carbon alloyed Fe40Mn40Co10Cr10 high entropy alloys. Mater. Lett. 2019, 236, 416-419. [CrossRef]

77. Tirunilai, A.; Hanemann, T.; Weiss, K.-P.; Freudenberger, J.; Heilmaier, M.; Kauffmann, A. Dislocation-based serrated plastic flow of high entropy alloys at cryogenic temperatures. Acta Mater. 2020, 200, 980-991. [CrossRef]

78. Naeem, M.; He, H.; Zhang, F.; Huang, H.; Harjo, S.; Kawasaki, T.; Wang, B.; Lan, S.; Wu, Z.; Wang, F.; et al. Cooperative deformation in high-entropy alloys at ultralow temperatures. Sci. Adv. 2020, 6, eaax4002. [CrossRef] [PubMed]

79. Woo, W.; Huang, E.-W.; Yeh, J.-W.; Choo, H.; Lee, C.; Tu, S.-Y. In-situ neutron diffraction studies on high-temperature deformation behavior in a CoCrFeMnNi high entropy alloy. Intermetallics 2015, 62, 1-6. [CrossRef]

80. He, J.; Zhu, C.; Zhou, D.; Liu, W.; Nieh, T.; Lu, Z. Steady state flow of the FeCoNiCrMn high entropy alloy at elevated temperatures. Intermetallics 2014, 55, 9-14. [CrossRef]

81. Wu, Z.; Bei, H.; Pharr, G.M.; George, E.P. Temperature dependence of the mechanical properties of equiatomic solid solution alloys with face-centered cubic crystal structures. Acta Mater. 2014, 81, 428-441. [CrossRef]

82. Gu, J.; Song, M. Annealing-induced abnormal hardening in a cold rolled CrMnFeCoNi high entropy alloy. Scr. Mater. 2019, 162, 345-349. [CrossRef]

83. Gu, J.; Ni, S.; Liu, Y.; Song, M. Regulating the strength and ductility of a cold rolled FeCrCoMnNi high-entropy alloy via annealing treatment. Mater. Sci. Eng. A 2019, 755, 289-294. [CrossRef]

84. Li, L.; Li, Z.; da Silva, A.K.; Peng, Z.; Zhao, H.; Gault, B.; Raabe, D. Segregation-driven grain boundary spinodal decomposition as a pathway for phase nucleation in a high-entropy alloy. Acta Mater. 2019, 178, 1-9. [CrossRef]

85. Nabizada, A.; Zarei-Hanzaki, A.; Abedi, H.; Barati, M.; Asghari-Rad, P.; Kim, H. The high temperature mechanical properties and the correlated microstructure/ texture evolutions of a TWIP high entropy alloy. Mater. Sci. Eng. A 2020, 802, 140600. [CrossRef]

86. Abbasi, E.; Dehghani, K. Hot tensile properties of CoCrFeMnNi(NbC) compositionally complex alloys. Mater. Sci. Eng. A 2020, 772, 138771. [CrossRef]

87. Wu, S.; Yang, T.; Cao, B.; Luan, J.; Jia, Y.; Xu, L.; Mu, Y.; Zhang, T.; Kong, H.; Tong, X.; et al. Multicomponent Ni-rich high-entropy alloy toughened with irregular-shaped precipitates and serrated grain boundaries. Scr. Mater. 2021, 204, 114066. [CrossRef]

88. Eleti, R.R.; Bhattacharjee, T.; Zhao, L.; Bhattacharjee, P.P.; Tsuji, N. Hot deformation behavior of CoCrFeMnNi FCC high entropy alloy. Mater. Chem. Phys. 2018, 210, 176-186. [CrossRef]

89. Stepanov, N.; Shaysultanov, D.; Yurchenko, N.; Zherebtsov, S.; Ladygin, A.; Salishchev, G.; Tikhonovsky, M. High temperature deformation behavior and dynamic recrystallization in CoCrFeNiMn high entropy alloy. Mater. Sci. Eng. A 2015, 636, 188-195. [CrossRef]

90. Eleti, R.R.; Bhattacharjee, T.; Shibata, A.; Tsuji, N. Unique deformation behavior and microstructure evolution in high temperature processing of HfNbTaTiZr refractory high entropy alloy. Acta Mater. 2019, 171, 132-145. [CrossRef]

91. Lee, K.; Bae, B.; Kang, J.-H.; Lim, K.; Na, Y. Multi-phase refining of an AlCoCrFeNi high entropy alloy by hot compression. Mater. Lett. 2017, 198, 81-84. [CrossRef]

92. Eleti, R.R.; Chokshi, A.H.; Shibata, A.; Tsuji, N. Unique high-temperature deformation dominated by grain boundary sliding in heterogeneous necklace structure formed by dynamic recrystallization in HfNbTaTiZr BCC refractory high entropy alloy. Acta Mater. 2020, 183, 64-77. [CrossRef]

93. Annasamy, M.; Haghdadi, N.; Taylor, A.; Hodgson, P.; Fabijanic, D. Dynamic recrystallization behaviour of AlxCoCrFeNi high entropy alloys during high-temperature plane strain compression. Mater. Sci. Eng. A 2019, 745, 90-106. [CrossRef]

94. Niu, S.; Kou, H.; Zhang, Y.; Wang, J.; Li, J. The characteristics of serration in Al0.5CoCrFeNi high entropy alloy. Mater. Sci. Eng. A 2017, 702, 96-103. [CrossRef]

95. Li, R.-D.; Niu, P.-D.; Yuan, T.-C.; Li, Z.-M. Displacive transformation as pathway to prevent micro-cracks induced by thermal stress in additively manufactured strong and ductile high-entropy alloys. Trans. Nonferrous Met. Soc. China 2021, 31, 1059-1073. [CrossRef]

96. Lu, W.; Liebscher, C.H.; Dehm, G.; Raabe, D.; Li, Z. Bidirectional Transformation Enables Hierarchical Nanolaminate Dual-Phase High-Entropy Alloys. Adv. Mater. 2018, 30, e1804727. [CrossRef]

97. Zhang, W.; Yan, D.; Lu, W.; Li, Z. Carbon and nitrogen co-doping enhances phase stability and mechanical properties of a metastable high-entropy alloy. J. Alloys Compd. 2020, 831, 154799. [CrossRef]

98. Zhu, S.; Yan, D.; Gan, K.; Lu, W.; Li, Z. Awakening the metastability of an interstitial high entropy alloy via severe deformation. Scr. Mater. 2021, 191, 96-100. [CrossRef] 
99. Jo, Y.H.; Yang, J.; Choi, W.-M.; Doh, K.-Y.; Lee, D.; Kim, H.S.; Lee, B.-J.; Sohn, S.S.; Lee, S. Body-centered-cubic martensite and the role on room-temperature tensile properties in Si-added SiVCrMnFeCo high-entropy alloys. J. Mater. Sci. Technol. 2021, 76, 222-230. [CrossRef]

100. Lilensten, L.; Couzinié, J.-P.; Bourgon, J.; Perrière, L.; Dirras, G.; Prima, F.; Guillot, I. Design and tensile properties of a bcc Ti-rich high-entropy alloy with transformation-induced plasticity. Mater. Res. Lett. 2016, 5, 110-116. [CrossRef]

101. Su, J.; Raabe, D.; Li, Z. Hierarchical microstructure design to tune the mechanical behavior of an interstitial TRIP-TWIP highentropy alloy. Acta Mater. 2019, 163, 40-54. [CrossRef]

102. Yang, J.; Jo, Y.H.; Kim, D.W.; Choi, W.-M.; Kim, H.S.; Lee, B.-J.; Sohn, S.S.; Lee, S. Effects of transformation-induced plasticity (TRIP) on tensile property improvement of $\mathrm{Fe}_{45} \mathrm{Co}_{30} \mathrm{Cr}_{10} \mathrm{~V}_{10} \mathrm{Ni}_{5-\mathrm{x}} \mathrm{Mn}_{\mathrm{x}}$ high-entropy alloys. Mater. Sci. Eng. A 2020, 772, 138809. [CrossRef]

103. Huang, G.L.; Matlock, D.; Krauss, G. Martensite formation, strain rate sensitivity, and deformation behavior of type 304 stainless steel sheet. Met. Mater. Trans. A 1989, 20, 1239-1246. [CrossRef]

104. Wang, X.; Zhou, W.; Liu, P.; Song, S.; Reddy, K.M. Atomic scale structural characterization of B2 phase precipitated along FCC twin boundary in a $\mathrm{CoCrFeNiAl}$..3 high entropy alloy. Scr. Mater. 2019, 162, 161-165. [CrossRef]

105. Santodonato, L.J.; Zhang, Y.; Feygenson, M.; Parish, C.M.; Gao, M.C.; Weber, R.J.; Neuefeind, J.C.; Tang, Z.; Liaw, P.K. Deviation from high-entropy configurations in the atomic distributions of a multi-principal-element alloy. Nat. Commun. 2015, 6, 5964. [CrossRef]

106. Wang, Z.; Lu, W.; Zhao, H.; Liebscher, C.H.; He, J.; Ponge, D.; Raabe, D.; Li, Z. Ultrastrong lightweight compositionally complex steels via dual-nanoprecipitation. Sci. Adv. 2020, 6, eaba9543. [CrossRef]

107. Feuerbacher, M. Dislocations and deformation microstructure in a B2-ordered $\mathrm{Al}_{28} \mathrm{Co}_{20} \mathrm{Cr}_{11} \mathrm{Fe}_{15} \mathrm{Ni}_{26}$ high-entropy alloy. Sci. Rep . 2016, 6, 29700. [CrossRef]

108. Chen, S.-T.; Tang, W.-Y.; Kuo, Y.-F.; Chen, S.-Y.; Tsau, C.-H.; Shun, T.-T.; Yeh, J.-W. Yeh, Microstructure and properties of age-hardenable $\mathrm{Al}_{x} \mathrm{CrFe}_{1.5} \mathrm{MnNi}_{0.5}$ alloys. Mater. Sci. Eng. A 2010, 527, 5818-5825. [CrossRef]

109. Ng, C.; Guo, S.; Luan, J.; Shi, S.-Q.; Liu, C.T. Entropy-driven phase stability and slow diffusion kinetics in an $\mathrm{Al}_{0.5} \mathrm{CoCrCuFeNi}$ high entropy alloy. Intermetallics 2012, 31, 165-172. [CrossRef]

110. Liu, W.; Lu, Z.; He, J.; Luan, J.; Wang, Z.; Liu, B.; Liu, Y.; Chen, M.; Liu, C. Ductile CoCrFeNiMox high entropy alloys strengthened by hard intermetallic phases. Acta Mater. 2016, 116, 332-342. [CrossRef]

111. Jo, Y.H.; Choi, W.-M.; Sohn, S.S.; Kim, H.S.; Lee, B.-J.; Lee, S. Role of brittle sigma phase in cryogenic-temperature-strength improvement of non-equi-atomic Fe-rich VCrMnFeCoNi high entropy alloys. Mater. Sci. Eng. A 2018, 724, 403-410. [CrossRef]

112. Shun, T.-T.; Chang, L.-Y.; Shiu, M.-H. Age-hardening of the CoCrFeNiMo 0.85 high-entropy alloy. Mater. Charact. 2013, 81, 92-96. [CrossRef]

113. Tsai, M.-H.; Yuan, H.; Cheng, G.; Xu, W.; Jian, W.W.; Chuang, M.-H.; Juan, C.-C.; Yeh, A.-C.; Lin, S.-J.; Zhu, Y. Significant hardening due to the formation of a sigma phase matrix in a high entropy alloy. Intermetallics 2013, 33, 81-86. [CrossRef]

114. Ming, K.; Bi, X.; Wang, J. Realizing strength-ductility combination of coarse-grained Al0.2Co1.5CrFeNi1.5Ti0.3 alloy via nanosized, coherent precipitates. Int. J. Plast. 2018, 100, 177-191. [CrossRef]

115. Shun, T.-T.; Hung, C.-H.; Lee, C.-F. Formation of ordered/disordered nanoparticles in FCC high entropy alloys. J. Alloys Compd. 2010, 493, 105-109. [CrossRef]

116. He, J.Y.; Wang, H.; Huang, H.L.; Xu, X.D.; Chen, M.W.; Wu, Y.; Liu, X.J.; Nieh, T.G.; An, K.; Lu, Z.P. A precipitation-hardened high-entropy alloy with outstanding tensile properties. Acta Mater. 2016, 102, 187-196. [CrossRef]

117. Kwon, H.; Moon, J.; Bae, J.W.; Park, J.M.; Son, S.; Do, H.-S.; Lee, B.-J.; Kim, H.S. Precipitation-driven metastability engineering of carbon-doped CoCrFeNiMo medium-entropy alloys at cryogenic temperature. Scr. Mater. 2020, 188, 140-145. [CrossRef]

118. He, J.; Wang, H.; Wu, Y.; Liu, X.; Nieh, T.; Lu, Z. High-temperature plastic flow of a precipitation-hardened FeCoNiCr high entropy alloy. Mater. Sci. Eng. A 2017, 686, 34-40. [CrossRef]

119. Zhang, L.; Zhou, Y.; Jin, X.; Du, X.; Li, B. The microstructure and high-temperature properties of novel nano precipitation-hardened face centered cubic high-entropy superalloys. Scr. Mater. 2018, 146, 226-230. [CrossRef]

120. Lu, W.; Liebscher, C.H.; Yan, F.; Fang, X.; Li, L.; Li, J.; Guo, W.; Dehm, G.; Raabe, D.; Li, Z. Interfacial nanophases stabilize nanotwins in high-entropy alloys. Acta Mater. 2020, 185, 218-232. [CrossRef]

121. Liu, X.; Gao, N.; Zheng, J.; Wu, Y.; Zhao, Y.; Chen, Q.; Zhou, W.; Pu, S.; Jiang, W.; Fan, Z. Improving high-temperature mechanical properties of cast $\mathrm{CrFeCoNi}$ high-entropy alloy by highly thermostable in-situ precipitated carbides. J. Mater. Sci. Technol. 2021, 72, 29-38. [CrossRef]

122. Yang, T.; Zhao, Y.; Fan, L.; Wei, J.; Luan, J.; Liu, W.; Wang, C.; Jiao, Z.; Kai, J.; Liu, C. Control of nanoscale precipitation and elimination of intermediate-temperature embrittlement in multicomponent high-entropy alloys. Acta Mater. 2020, 189, 47-59. [CrossRef]

123. Bönisch, M.; Wu, Y.; Sehitoglu, H. Twinning-induced strain hardening in dual-phase $\mathrm{FeCoCrNiAl}_{0.5}$ at room and cryogenic temperature. Sci. Rep. 2018, 8, 1-9. [CrossRef]

124. Abuzaid, W.; Sehitoglu, H. Plastic strain partitioning in dual phase $\mathrm{Al}_{13} \mathrm{CoCrFeNi}$ high entropy alloy. Mater. Sci. Eng. A 2018, 720, 238-247. [CrossRef] 
125. Shi, P.; Ren, W.; Zheng, T.; Ren, Z.; Hou, X.; Peng, J.; Hu, P.; Gao, Y.; Zhong, Y.; Liaw, P.K. Enhanced strength-ductility synergy in ultrafine-grained eutectic high-entropy alloys by inheriting microstructural lamellae. Nat. Commun. 2019, 10, 489. [CrossRef] [PubMed]

126. Wu, G.; Balachandran, S.; Gault, B.; Xia, W.; Liu, C.; Rao, Z.; Wei, Y.; Liu, S.; Lu, J.; Herbig, M.; et al. Crystal-Glass High-Entropy Nanocomposites with Near Theoretical Compressive Strength and Large Deformability. Adv. Mater. 2020, 32, 2002619. [CrossRef] [PubMed]

127. Lu, Y.; Gao, X.; Jiang, L.; Chen, Z.; Wang, T.; Jie, J.; Kang, H.; Zhang, Y.; Guo, S.; Ruan, H.; et al. Directly cast bulk eutectic and near-eutectic high entropy alloys with balanced strength and ductility in a wide temperature range. Acta Mater. 2017, 124, 143-150. [CrossRef]

128. Bhattacharjee, T.; Zheng, R.; Chong, Y.; Sheikh, S.; Guo, S.; Clark, I.T.; Okawa, T.; Wani, I.S.; Bhattacharjee, P.; Shibata, A.; et al. Effect of low temperature on tensile properties of AlCoCrFeNi2.1 eutectic high entropy alloy. Mater. Chem. Phys. 2018, 210, 207-212. [CrossRef]

129. Jaladurgam, N.R.; Lozinko, A.; Guo, S.; Lee, T.-L.; Colliander, M.H. Temperature dependent load partitioning and slip mode transition in a eutectic $\mathrm{AlCoCrFeNi}_{2.1}$ high entropy alloy. Materialia 2021, 17, 1011188. [CrossRef]

130. Zhang, Y.; Wang, X.; Li, J.; Huang, Y.; Lu, Y.; Sun, X. Deformation mechanism during high-temperature tensile test in an eutectic high-entropy alloy AlCoCrFeNi 2.1 . Mater. Sci. Eng. A 2018, 724, 148-155. [CrossRef]

131. Guo, Y.; He, J.; Lu, W.; Jia, L.; Li, Z. The evolution of compositional and microstructural heterogeneities in a TaMo $\mathrm{Mo}_{0.5} \mathrm{ZrTi}_{1.5} \mathrm{Al}_{0.1} \mathrm{Si}_{0.2}$ high entropy alloy. Mater. Charact. 2021, 172, 110836. [CrossRef]

132. Shah, N.; Rahul, M.; Bysakh, S.; Phanikumar, G. Microstructure stability during high temperature deformation of CoCrFeNiTa eutectic high entropy alloy through nano-scale precipitation. Mater. Sci. Eng. A 2021, 824, 141793. [CrossRef]

133. Moravcik, I.; Peighambardoust, N.S.; Motallebzadeh, A.; Moravcikova-Gouvea, L.; Liu, C.; Prabhakar, J.M.; Dlouhy, I.; Li, Z. Interstitial nitrogen enhances corrosion resistance of an equiatomic CoCrNi medium-entropy alloy in sulfuric acid solution. Mater. Charact. 2021, 172, 110869. [CrossRef]

134. Fu, Z.; Wu, P.; Zhu, S.; Gan, K.; Yan, D.; Li, Z. Effects of interstitial C and N on hydrogen embrittlement behavior of non-equiatomic metastable FeMnCoCr high-entropy alloys. Corros. Sci. 2021, 194, 109933. [CrossRef]

135. Soundararajan, C.K.; Luo, H.; Raabe, D.; Li, Z. Hydrogen resistance of a 1 GPa strong equiatomic CoCrNi medium entropy alloy. Corros. Sci. 2020, 167, 108510. [CrossRef]

136. Rao, Z.; Dutta, B.; Körmann, F.; Ponge, D.; Li, L.; He, J.; Stephenson, L.; Schäfer, L.; Skokov, K.; Gutfleisch, O.; et al. Unveiling the mechanism of abnormal magnetic behavior of FeNiCoMnCu high-entropy alloys through a joint experimental-theoretical study. Phys. Rev. Mater. 2020, 4, 014402. [CrossRef]

137. Rao, Z.; Ponge, D.; Körmann, F.; Ikeda, Y.; Schneeweiss, O.; Friák, M.; Neugebauer, J.; Raabe, D.; Li, Z. Invar effects in FeNiCo medium entropy alloys: From an Invar treasure map to alloy design. Intermetallics 2019, 111, 106520. [CrossRef]

138. Rao, Z.; Çakır, A.; Özgün, Ö.; Ponge, D.; Raabe, D.; Li, Z.; Acet, M. 3d transition-metal high-entropy Invar alloy developed by adjusting the valence-electron concentration. Phys. Rev. Mater. 2021, 5, 044406. [CrossRef]

139. Von Rohr, F.; Winiarski, M.; Tao, J.; Klimczuk, T.; Cava, R.J. Effect of electron count and chemical complexity in the Ta-Nb-Hf-Zr-Ti high-entropy alloy superconductor. Proc. Natl. Acad. Sci. USA 2016, 113, E7144-E7150. [CrossRef]

140. Shafeie, S.; Guo, S.; Hu, Q.; Fahlquist, H.; Erhart, P.; Palmqvist, A. High-entropy alloys as high-temperature thermoelectric materials. J. Appl. Phys. 2015, 118, 184905. [CrossRef]

141. Koželj, P.; Vrtnik, S.; Jelen, A.; Jazbec, S.; Jagličić, Z.; Maiti, S.; Feuerbacher, M.; Steurer, W.; Dolinšek, J. Discovery of a Superconducting High-Entropy Alloy. Phys. Rev. Lett. 2014, 113, 107001. [CrossRef] [PubMed] 